\title{
Keratins couple with the nuclear lamina and regulate proliferation in colonic epithelial cells
}

Carl-Gustaf A. Stenvall ${ }^{*}$, Joel H. Nyström ${ }^{1 *}$, Ciarán Butler-Hallissey ${ }^{1,5}$, Stephen A. Adam², Roland Foisner ${ }^{3}$, Karen M. Ridge ${ }^{2}$, Robert D. Goldman ${ }^{2}$, Diana M. Toivola ${ }^{1,4}$

1 Cell Biology, Biosciences, Faculty of Science and Engineering, Åbo Akademi University, Turku, Finland

2 Department of Cell and Developmental Biology, Feinberg School of Medicine, Northwestern University, Chicago, Illinois, USA

3 Max Perutz Labs, Medical University of Vienna, Vienna Biocenter Campus (VBC), Vienna, Austria

4 Turku Center for Disease Modeling, Turku, Finland

5 Turku Bioscience Centre, University of Turku and Åbo Akademi University, Turku, Finland

* indicates equal contribution

Running Head: Colonocyte keratins couple to nuclear lamina

\section{Corresponding author:}

Diana M. Toivola

Cell Biology/Biosciences, Faculty of Science and Engineering, Åbo Akademi University

Tykistökatu 6A, FIN-20520 Turku, Finland

Telephone: +35822154092

E-mail: dtoivola@abo.fi

Keywords: Keratins, lamin, intermediate filament, colon epithelial cells, LINC proteins, proliferation, $\mathrm{pRb}, \mathrm{YAP}$ 


\begin{abstract}
Keratin intermediate filaments (IFs) convey mechanical stability and protection against stress to epithelial cells, and may participate in nuclear structure and organization. Keratins are important for colon health as observed in keratin 8 knockout $\left(\mathrm{K}^{-/-}\right)$mice, which exhibit colonic inflammation and epithelial hyperproliferation. Here, using a full body and two intestinal epithelial-specific $\mathrm{K}^{-/-}$knockout mouse models, we determine if cytoplasmic keratins affect the nuclear structure and lamina in epithelial colonocytes. $\mathrm{K} 8^{-/}$colonocytes in vivo and in organoid cultures exhibit significantly decreased levels of the major lamins A/C, B1 and B2 in a colon-specific and cell-intrinsic manner independent of major changes in colonic inflammation or microbiota. Downregulation of K8 by siRNA in Caco-2 cells similarly decreases lamin A levels, which recover after re-expression of K8. K8 loss is associated with reduced plectin, LINC complex proteins and lamin-associated proteins, indicating a dysfunctional keratin-nuclear lamina coupling. Immunoprecipitation identifies complexes of colonocyte keratins with the LINC protein SUN2 and lamin A. Hyperphosphorylation of the lamin A-associated cell cycle regulator $\mathrm{pRb}$ in $\mathrm{K}^{-/-}$colonocytes together with increased nuclear localization of the mechanosensor YAP provide a molecular mechanism for the hyperproliferation phenotype. These findings identify a novel, colonocyte-specific role for K8 in nuclear function.
\end{abstract}




\section{Introduction}

Keratins (K) are the most abundant intermediate filament (IF) proteins and divided into acidic type I keratins (K9-28) and basic/neutral type II keratins (K1-8 and K71-80) (Schweizer et al., 2006). Keratins form obligatory non-covalent heteropolymers in epithelial cells (Coulombe and Omary, 2002), and the main simple epithelial keratins in the colonic epithelium are K7 and K8 (type II), and K18, K19 and K20 (type I) (Zhou et al., 2003). Keratins have multiple functions, including providing cell stress protection, mechanical stability, protein and organelle scaffolding, and modulating protein targeting in cells and tissues (Toivola et al., 2005; Omary, 2017). Several diseases have been linked to keratin mutations, e.g. in skin and liver, while their role in colon and inflammatory bowel diseases (IBD) are still unclear (Coulombe et al., 1991; Ku et al., 2003; Toivola et al., 2015; Omary, 2017). However, K8 knockout (K8 $\left.{ }^{-/-}\right)$mice display a colonic phenotype marked by colitis, epithelial hyperproliferation, mistargeting and/or downregulation of membrane proteins (e.g. ion transporters) leading to diarrhea, deregulated epithelial differentiation and blunted colonocyte energy metabolism (Baribault et al., 1994; Toivola et al., 2004; Helenius et al., 2015; Asghar et al., 2016; Lähdeniemi et al., 2017). K8 $8^{+/-}$ mice, which express $50 \%$ less keratins than $\mathrm{K}^{+/+}$mice, exhibit an intermediate phenotype with moderate hyperproliferation, a partial ion transport defect, an increased susceptibility to experimental colitis, but no obvious spontaneous colitis under basal conditions (Asghar et al., 2015; Asghar et al., 2016; Liu et al., 2017). Interestingly, $\mathrm{K} 8^{-/-}$mice in two models of colorectal cancer (Misiorek et al., 2016), and $\mathrm{K}^{+/-}$in a model combining chemical colitis and colorectal cancer (Liu et al., 2017), are highly susceptible to induced colorectal cancer. The colitis and hyperproliferation in $\mathrm{K}^{-/-}$mice (Habtezion et al., 2005) and the tumor load in $\mathrm{K}^{+/-}$(Liu et al., 2017) can be partly ameliorated with antibiotics (Habtezion et al., 2005), indicating that the microbiota plays a crucial part in these K8-deficient colon phenotypes.

The nuclear lamina is a filamentous meshwork beneath the inner nuclear membrane (INM) that is composed of type V IF proteins, the nuclear A- and B-type lamins, and INM proteins (Wilson and Foisner, 2010). A-type lamins, mainly lamins A and C, are encoded from the LMNA gene through alternative splicing, and B-type lamins, primarily lamins B1 and B2, are encoded by the LMNB1 and LMNB2 genes, respectively (Dechat et al., 2008). Lamins are important for many nuclear processes, including maintenance of nuclear morphology and integrity, mechanotransduction, chromatin organization, gene expression, differentiation and proliferation (Dechat et al., 2010; Wilson and Foisner, 2010; Naetar et al., 2017; Brady et al., 2018; de Leeuw et al., 2018). These processes involve interactions between lamins and a 
multitude of lamin-binding proteins in the INM, nucleoplasm and chromatin, including LAP2Emerin-MAN1 (LEM)-domain proteins, lamin B receptor (LBR) and SUN proteins (Wagner and Krohne, 2007; Wilson and Foisner, 2010). For example, a nucleoplasmic LEM-domain protein, lamina-associated polypeptide $2 \alpha(\mathrm{LAP} 2 \alpha)$, is crucial for maintaining and regulating a pool of nucleoplasmic lamin A/C (Naetar et al., 2008). LAP2 $\alpha$ and nucleoplasmic lamin A/C interact with and promote the activity of the cell cycle repressor retinoblastoma protein $(\mathrm{pRb})$, thus controlling and inhibiting cell proliferation (Naetar et al., 2008; Gesson et al., 2014; Vidak et al., 2018). Mutations in the lamin genes, mainly in the LMNA gene, cause many severe diseases termed laminopathies, such as Hutchinson-Gilford progeria syndrome (HGPS), muscular dystrophies and cardiomyopathies (Worman, 2012).

The nuclear lamina and the cytoskeleton are connected through LINC complexes, which are important for nuclear morphology, positioning and mechanotransduction (Crisp et al., 2006; Tapley and Starr, 2013; Osmanagic-Myers et al., 2015). LINC complexes are composed of outer nuclear membrane (ONM) KASH proteins, nesprins, that are connected to INM SUN proteins (Crisp et al., 2006). The cytoskeleton binds LINC complexes either directly or through cytolinker proteins, such as plectin, and, for example, epidermal keratin IFs in keratinocytes and mesenchymal vimentin IFs are connected to nesprin-3 through plectin (Wilhelmsen et al., 2005; Ketema et al., 2013; Almeida et al., 2015). Little is known about lamin and keratin synergy, however, epidermal K1/K10 loss has been linked to premature loss of nuclei, impaired nuclear integrity and decreased lamin A/C, emerin and SUN1 protein levels (Wallace et al., 2012), and K14 loss in epidermal keratinocytes leads to aberrations in the shape and size of the nucleus (Lee et al., 2012). Importantly, the role of simple-type epithelial keratins in regulating nuclear lamin function, especially in the colonic epithelium, is unknown (Brady et al., 2018). As we hypothesize that simple epithelial keratins may regulate lamins and the nucleus, the objective of this study was to assess if the loss of these keratins affect lamins and laminassociated proteins in $\mathrm{K}^{-/-}$colonocytes. Here, we show for the first time that lamin protein levels correlate with keratin levels particularly in colonocytes, and that cytoplasmic keratins complex with lamins and couple to the nuclear lamina. Furthermore, the colon hyperproliferation observed in $\mathrm{K}^{-/-}$mice is a likely consequence of keratin-related changes in LINC complex and lamin-associated proteins. 


\section{Results}

\section{Loss of simple epithelial K8 correlates with decreased lamin levels in murine colonic epithelial cells in vivo.}

To determine whether simple epithelial keratins influence nuclear lamins in colonic epithelial cells, wee first analyzed lamin A, B and C levels in the colonic epithelium as a function of keratin levels using $\mathrm{K} 8^{-/-}$mice, in which most colonocyte keratins are depleted except for a thin keratin-layer at the apical membrane (Asghar et al., 2015).

Western blot analysis of crudely isolated colonic epithelial cells from $\mathrm{K}^{+/+}, \mathrm{K} 8^{-/-}$and $\mathrm{K} 8^{+/-}$ mice revealed significantly decreased protein levels of all major lamins, i.e. lamins A (2-fold), $\mathrm{C}$ (3-fold), B1 (5-fold) and B2 (10-fold), in $\mathrm{K}^{-/-}$mouse colonocytes compared to $\mathrm{K}^{+/+}$(Fig. 1A-F). $\mathrm{K}^{+/-}$colonocytes also exhibited significantly decreased lamin B2 protein levels (2fold), but in contrast to $\mathrm{K}^{-/-}$, the decrease was moderate (Fig. 1F). In addition, the levels of lamin A S22 phosphorylation (lamin A pS22) was decreased when adjusted for total lamin A protein levels in $\mathrm{K}^{-/-}$mouse colonocytes compared to $\mathrm{K} 8^{+/+}$(Fig. 1C). Lamin gene expression analysis by qRT-PCR showed that there was no significant change in lamin B1 mRNA levels, while lamin $\mathrm{A} / \mathrm{C}$ and laminB2 mRNA levels were decreased on average by $50 \%$ in $\mathrm{K} 8^{-/-}$ colonocytes compared to $\mathrm{K}^{+/+}$(Supplemental Fig. 1). Taken together, these data show that the protein levels of the major lamin isoforms $\mathrm{A}, \mathrm{C}, \mathrm{B} 1$ and $\mathrm{B} 2$ are decreased in $\mathrm{K} 8^{-/-}$colonocytes, to a lesser but generally intermediate extent in $\mathrm{K}^{+/-}$colonocytes, and that the downregulation is associated with decreased lamin gene expression, apart for lamin B1.

\section{Lamin downregulation in the absence of $\mathrm{K8}$ is specific for epithelial cells in the colon.}

To carefully define the location of the decreased lamin levels seen in $\mathrm{K} 8^{-/-}$colon, lamin $\mathrm{A}$ immunostaining was performed on $\mathrm{K}^{+/+}$and $\mathrm{K}^{-/-}$colon. $\mathrm{K}^{+/+}$colonocytes express lamin $\mathrm{A}$ along the whole crypt, while clearly less lamin A was observed in the entire $\mathrm{K}^{-/-}$crypt compared to $\mathrm{K}^{+/+}$(Fig. 2A-B). Furthermore, $\mathrm{K}^{-/-}$lamin A levels were unaffected in nonepithelial cells of the lamina propria and the submucosa (Fig. 2A-B), showing that the loss of lamin occurs in the keratin-expressing epithelial cells.

We next asked if the loss of lamins in the keratin-deficient colon seen in the full $\mathrm{K}^{-/-}$mouse is colonocyte-autonomous, and for this colon-specific $\mathrm{K} 8^{-/-}$mice were established using the floxVillin-Cre system. $\mathrm{K} 8^{\text {flox/flox }}$ mice were bred with either Villin-Cre or Villin-CreEr ${ }^{\mathrm{T} 2}$ mice to generate K8 knockdown specifically in the intestinal epithelial cells (mucosal crypt layer). 
$\mathrm{K} 8^{\text {flox/flox}}$;Villin-Cre mice are K8-deficient from birth, while the loss of K8 expression in $\mathrm{K} 8^{\text {flox/flox;}}$;Villin-CreER ${ }^{\mathrm{T} 2}$ mice is tamoxifen-inducible (1 injection/day for 5 days, whereafter mice were sacrificed after 25 days). In both colon-specific $\mathrm{K} 8^{-/-}$mouse models, lamin $\mathrm{A}$ and B1 protein levels were decreased in colonocytes in vivo (Fig. 2C-F and Supplemental Fig. 2A), implying that this phenotype is indeed colonocyte-intrinsic. Additionally, a similar reduction of lamin $\mathrm{A} / \mathrm{C}$ protein levels, as seen in vivo (Fig. 1A, B and D), was observed ex vivo in $\mathrm{K} 8^{\text {flox/flox}}$;Villin-Cre-ER ${ }^{\mathrm{T} 2}$ mouse colon $3 \mathrm{D}$ cultured organoids displaying an almost complete knockdown of K8 following tamoxifen-induced gene deletion (Supplemental Fig. 2B).

To assess if lamins are affected in other epithelial tissues normally expressing K8, lamin protein levels were analyzed in the small intestine (ileum), liver, pancreas and lung. In contrast to the $\mathrm{K} 8^{-/-}$colon, the small intestine in $\mathrm{K}^{-/-}$mice has a mild or negligible disease phenotype and does not display major hyperproliferation nor inflammation (Baribault et al., 1994; Ameen et al., 2001). The lamin A, B1/B2 and C protein levels in total lysates of the most distal part of the small intestine (ileum) were unchanged in $\mathrm{K} 8^{-/-}$mice compared to $\mathrm{K} 8^{+/+}$mice (Fig. 3). Similarly, no changes in lamin A levels were observed in total lysates of $\mathrm{K}^{-/-}$liver, pancreas and lung, while a decrease was observed in $\mathrm{K}^{-/-}$colon total lysates (Supplemental Fig. 3A-D). Taken together, these findings identify a colon and colonocyte-specific role for keratins in the regulation of lamin protein levels.

\section{The colitis and microbiota levels do not contribute to lamin downregulation in $\mathrm{K8}^{-/-}$mouse colon.}

The colonic microbiota plays a crucial role in the $\mathrm{K}^{-/-}$colon phenotype, as depletion of the colonic microbiota by broad-spectrum antibiotic treatment decreases inflammation and hyperproliferation in $\mathrm{K}^{-/-}$mice (Habtezion et al., 2005; Habtezion et al., 2011). Therefore, the impact of inflammation and microbiota on lamin protein expression was assessed in colonocytes from $\mathrm{K}^{+/+}$and $\mathrm{K}^{-/-}$mice treated with broad-spectrum antibiotics. Antibiotic treatment did not elicit any changes in, or normalization of, $\mathrm{K}^{-/-}$colonocyte lamin protein levels compared to control (baseline) mice (Fig. 4A). Decreased neutrophil infiltration in $\mathrm{K}^{-}$ /- colon, as seen by myeloperoxidase staining, confirmed that the antibiotic treatment ameliorated the inflammation in $\mathrm{K}^{-/-}$colon (Fig. 4B) (Asghar et al., 2015). Moreover, lamin $\mathrm{A}, \mathrm{B} 1$ and $\mathrm{C}$ protein levels remained unchanged in $\mathrm{K}^{+/+}$mice treated with the colitis-inducing chemical dextran sodium sulfate (DSS) compared to untreated mice (Supplemental Fig. 3E-H). These findings exclude the colonic microbiota and the colitis observed in $\mathrm{K}^{-/-}$colon as major 
contributing factors for the lamin changes and suggest a more direct role for keratins in the observed lamin phenotype.

Keratins maintain lamin levels in colorectal adenocarcinoma cells. To assess whether the effect of K8 downregulation on colonocyte lamin levels in vivo is reproducible in vitro, human colorectal adenocarcinoma Caco-2 cells were subjected to sustained treatment with $\mathrm{K} 8$ and $\mathrm{K} 18$ siRNAs. Robust knockdown of keratins (about $80 \%$ ) elicited a significant decrease in lamin A (about $40 \%$ ) and lamin B1 (about $20 \%$ ) protein levels (Fig. 5A-E). Immunofluorescence staining of K8/K18 siRNA-treated cells showed a similar decrease of lamin A levels in cells lacking K8/K18, while the decrease in lamin B1 levels was not as obvious (Fig. 5F). This leads to an apparent shift in the lamin A/B ratio, with lamin B1 appearing more prominent than lamin A in cells lacking $\mathrm{K} 8 / \mathrm{K} 18$, which is supported by the more robust keratin-dependent decrease of lamin A compared to lamin B1 in siRNA-treated cells (Fig. 5D-E). Importantly, allowing siRNA-treated cells to recover for 9 days after siRNA treatment completely normalized K8/K18 protein levels (Fig. 5 A-C), simultaneously rescuing the lamin A and B1 phenotype (Fig. 5BE), indicating that lamin protein levels correlate with keratin levels in colon epithelial cells.

\section{LINC complex protein levels are decreased in $\mathrm{K8}^{-/-}$mouse colonocytes and correlate with}

increased nuclear translocation of YAP. Loss of K1/K10 disrupts nuclear integrity and may decouple the cytoskeleton and nucleus in the epidermis (Wallace et al., 2012). To assess whether nucleo-cytoskeletal coupling and nuclear integrity may be connected to $\mathrm{K} 8$ in colonocytes, the levels of the cytolinker protein plectin and several LINC complex and laminassociated proteins were assayed. SUN1, SUN2 and the INM protein emerin had reduced gene expression in $\mathrm{K}^{-/-}$colonocytes as seen by qRT-PCR, while no change was seen in plectin or nesprin-3 mRNA levels (Supplemental Fig. 4A). However, the decrease in SUN1, SUN2 and emerin protein levels in $\mathrm{K}^{-/-}$colonocytes was larger than indicated by the qRT-PCR analysis, while also plectin protein levels were decreased significantly (Fig. 6A-E). Furthermore, SUN1 and emerin protein levels in $\mathrm{K} 8^{+/-}$colonocytes were moderately decreased compared to $\mathrm{K} 8^{+/+}$ colonocytes (Fig. 6E). Additionally, SUN2 protein levels were unchanged in the small intestine (ileum) of $\mathrm{K}^{-/-}$mice compared to $\mathrm{K}^{+/+}$(Supplemental Fig. 4B), indicating that the keratinassociated effect on LINC and lamin-associated proteins is colon-specific.

To understand the molecular connection between cytoplasmic keratins and nuclear lamins, K8/K18 or lamin A co-immunoprecipitation assays were performed on lysates of Caco-2 cells. K8/K18 co-immunoprecipitated with lamin A and the LINC protein SUN2 while, conversely, lamin A co-immunoprecipitated K8, K18 and K19 (Fig. 6F-G). These data indicate that keratins 
can complex with LINC complexes and lamins, suggesting that keratins could physically link to the lamina via the LINC complex and may thus affect the mechanical properties of the nucleus and nuclear mechanotransduction, and thereby modulate nuclear function.

The mechanosensitive transcriptional regulator Yes-associated protein (YAP) has been implicated as an important integrator of mechanotransduction, proliferation as well as regeneration in the colon, and the loss of YAP impairs colon tissue regeneration upon injury (Cai et al., 2010; Yui et al., 2018). As mechanical regulation of YAP involves the actomyosin cytoskeleton, Src family kinases and intact LINC complexes (Elosegui-Artola et al., 2017; Ege et al., 2018), and LINC complex and LINC complex-associated proteins important for mechanotransduction are downregulated in $\mathrm{K}^{-/-}$colonocytes (figure 6) (Lombardi and Lammerding, 2011), the cellular localization and nuclear translocation of YAP was investigated to test whether the keratin cytoskeleton may be involved in mechanical regulation. In $\mathrm{K}^{+/+}$colonocytes, YAP levels were higher in the crypt bottom (Fig. 7A), where lamin levels are relatively low (Fig. 2A-B), compared to higher up in the crypt. Interestingly, $\mathrm{K}^{-/-}$ colonocytes, which have decreased lamin levels (Fig. 1) and are nearly keratin-free (Asghar et al., 2015), showed a clearly increased nuclear translocation of YAP compared to $\mathrm{K} 8^{+/+}$ colonocytes (Fig. 7A), while YAP protein levels were comparable in $\mathrm{K}^{+/+}$and $\mathrm{K}^{-/-}$ colonocytes. In vitro, Caco-2 cells treated with K8/K18 siRNA exhibit decreased cytoplasmic YAP compared to mock-transfected (data not shown) or K8/K18 scramble siRNA-transfected cells, while the levels of nuclear YAP appears similar or slightly elevated in K8/K18 siRNAtreated cells compared to controls (Fig. 7B), supporting the in vivo data. Interestingly, similar to K8/K18 scramble siRNA-transfected cells, the few K8-retaining cells in K8/K18 siRNAtreated cell cultures show higher cytoplasmic YAP compared to cells lacking K8 (Fig. 7B). These results support the notion that keratins may be involved in the mechanical coupling between the cytoskeleton and the nucleus in colonic epithelial cells.

\section{Lamin-associated protein $\mathrm{pRb}$ is hyperphosphorylated in $\mathrm{KB}^{-/-}$mouse colonocytes,} implying a disturbance in cell cycle regulation. We next addressed the mechanism involved in linking K8 and proliferation. Since changes in lamin B1 levels have previously been associated with the regulation of proliferation and senescence (Shimi et al., 2011; Barascu et al., 2012; Freund et al., 2012), the prevalence of senescence in the colon was analyzed using senescence-associated $\beta$-galactosidase staining in both proximal colon (PC) and distal colon (DC) of $\mathrm{K}^{+/+}$and $\mathrm{K}^{-/-}$mice. In both $\mathrm{K}^{-/-} \mathrm{PC}$ and DC the number of senescent cells was 
decreased compared to $\mathrm{K}^{+/+}$mice (Supplemental Fig. 5), indicating that the keratin-loss dependent lamin B1 reduction is clearly not increasing senescence.

A-type lamins bind LAP2 $\alpha$, and together they interact with and promote pRb-mediated inhibition of cell cycle progression, and consequently, proliferation (Naetar et al., 2008). As $\mathrm{K} 8^{-/-}$mouse colon is characterized by hyperproliferation (Baribault et al., 1994), and lamins $\mathrm{A} / \mathrm{C}$ are downregulated in $\mathrm{K}^{-/-}$colonocytes (Fig. 1), $\mathrm{K}^{+/+}, \mathrm{K}^{-/-}$and $\mathrm{K} 8^{+/-}$colonocytes were analyzed for the protein levels of LAP $2 \alpha$ and pRb, and the levels of phosphorylated $p R b$ (phosphor-Ser 807 and phoshpo-Ser 811), which constitutes the inactive form of $\mathrm{pRb}$ (Weinberg, 1995; Gesson et al., 2014). No significant changes in LAP2 $\alpha$ nor pRb protein (Fig. 7C) or LAP $2 \alpha$ mRNA levels (Supplemental Fig. 4A) were seen in $\mathrm{K}^{-/-}$colonocytes, however, $\mathrm{pRb}$ was highly hyperphosphorylated (3-fold compared to $\mathrm{K} 8^{+/+}$and $\mathrm{K}^{+/-}$colonocytes when normalized to $\mathrm{pRb}$ ) (Fig. $7 \mathrm{C}$ ), indicating that $\mathrm{pRb}$ may be inactivated in $\mathrm{K}^{-{ }^{--}}$colonocytes. Since keratins affect lamin and lamin-associated protein levels, we tested if the reverse relationship occurs. Analysis of LAP $2 \alpha^{-/-}$mice, which exhibit epithelial hyperproliferation and increased $\mathrm{pRb}$ phosphorylation in the skin, and an increased amount of proliferating transit amplifying cells in the colon (Naetar et al., 2008), showed no change in either keratin nor lamin protein levels in LAP $2 \alpha^{-/-}$colonocytes (Supplemental Fig. 4C). This suggests that the complex containing lamin $\mathrm{A} / \mathrm{C}, \mathrm{LAP} 2 \alpha$ and $\mathrm{pRb}$ is downstream of keratin-lamin interaction, and hence, loss of LAP $2 \alpha$ does not alter keratin protein levels.

\section{Discussion}

In this study, we demonstrate for the first time to our knowledge a molecular link between cytoplasmic simple epithelial keratins (K8 and its main partners K18 and K19), LINC complex proteins, lamin-associated proteins and nuclear lamins in colonocytes (summarized in Fig. 8). We show that the absence of keratins in colon epithelial cells leads to significantly decreased protein levels of the major lamin isoforms A, C, B1 and B2 in vivo in $\mathrm{K}^{-/-}$mice. Similarly, lamin A and B1 protein levels decrease in vitro in human Caco-2 cells treated with K8/K18 siRNA, and ex vivo in $\mathrm{K}^{\text {flox/flox }}$ Villin-Cre-ER ${ }^{\mathrm{T} 2} 3 \mathrm{D}$ colon organoids. Reduced lamin gene expression, except for lamin B1, is likely the cause for the decreased lamin protein levels observed in $\mathrm{K}^{-/-}$colon, however, it is unclear how the loss of keratins could affect lamin expression, as little is known about lamin gene regulation (Dechat et al., 2008). Interestingly, the decrease in lamin protein levels was colon-specific, as several other $\mathrm{K}^{-/-}$simple epithelial 
tissues, where K8 is a major or the only type II keratin, exhibited normal lamin levels, including normal SUN2 protein levels as assessed for the small intestine. The correlation between keratin loss and decreased lamin levels is likely independent of the microbiota or colitis observed in $\mathrm{K} 8^{-/-}$mice, as antibiotic treatment, which eliminates the colonic microbiota and ameliorates the colitis and hyperproliferation (Habtezion et al., 2011), did not normalize lamin levels. Very little is known regarding the potential roles of lamins in colon homeostasis and function (Brady et al., 2018). Low levels of A-type lamins correlate with increased gastric polyp size (Wang et al., 2015), and loss of A-type lamins in stage II and III colorectal cancers (CRC) puts patients at severe risk of cancer resurgence (Belt et al., 2011). Since the lack or decreased levels of colonic keratins leads to hyperproliferation and increased susceptibility to CRC tumorigenesis (Misiorek et al., 2016; Liu et al., 2017), the lamin phenotype in these mice may be a contributing factor toward the pro-tumorigenic phenotype. Nevertheless, intestinal epithelialspecific lamin A knockdown in mice did not lead to increased proliferation as measured by ki67 (Wang et al., 2015).

Lamin-associated proteins depend on A-type lamins, and vice versa, for stabilization and correct positioning in the nucleus (Vaughan et al., 2001; Libotte et al., 2005; Naetar et al., 2008; Muchir et al., 2009). Our data show that $\mathrm{K}^{-/-}$mouse colonocytes have decreased levels of emerin, which is anchored to the inner nuclear membrane by lamin A, and therefore the absence of emerin could be caused by decreased lamin A protein levels (Vaughan et al., 2001; Muchir et al., 2009). LAP2 $\alpha$ is essential for maintaining a nucleoplasmic pool of A-type lamins (Dechat et al., 2000; Naetar et al., 2008), and together with lamin A/C stabilizes and promotes the activity of the important cell cycle regulator pRb (Markiewicz et al., 2002; Naetar et al., 2008; Gesson et al., 2014). In the present study, LAP $2 \alpha$ and pRb levels were comparable in $\mathrm{K}^{+/+}$and $\mathrm{K} 8^{-/-}$colonocytes, while, in contrast, $\mathrm{pRb}$ was hyperphosphorylated in $\mathrm{K} 8^{-/-}$colonocytes. $\mathrm{pRb}$ mediated cell cycle regulation is phosphorylation-dependent, as active, hypophosphorylated $\mathrm{pRb}$ inhibits cell cycle progression, while hyperphosphorylation leads to its inactivation, causing increased cell cycle progression and proliferation (Weinberg, 1995; Gesson et al., 2014). Thus, the increased hyperphosphorylation of $\mathrm{pRb}$ in $\mathrm{K} 8^{-/-}$colonocytes could be a major contributing factor to the hyperproliferation observed in $\mathrm{K}^{-/-}$mice (Baribault et al., 1994; Naetar et al., 2008; Gesson et al., 2014). Intriguingly, similar to $\mathrm{K}^{-/-}$mice (Lähdeniemi et al., 2017), LAP $2 \alpha^{-/-}$mice were reported to exhibit an upregulation of proliferating transit amplifying cells and enhanced colonic proliferation caused by LAP $2 \alpha$-loss-mediated depletion of nucleoplasmic A-type lamins and inactivation of $\mathrm{pRb}$ through phosphorylation (Naetar et al., 
2008). However, we observed no major changes in keratin or lamin levels in LAP $2 \alpha^{-/-}$ colonocytes (Supplemental Fig. 4C). Similarly, the loss of A-type lamins in mice causes mild epidermal hyperplasia comparable to that seen in LAP $2 \alpha^{-/-}$mice (Naetar et al., 2008), and pRb loss in mice leads to hyperproliferation and stimulates the differentiation of enterocytes, goblet cells, enteroendocrine cells and Paneth cells in the small intestine (Yang and Hinds, 2007). While we cannot rule out a more direct role of $\mathrm{K} 8$ in nuclear function similar to K17, which was recently shown to enter the nucleus where it can modulate several signaling pathways (Escobar-Hoyos et al., 2015; Hobbs et al., 2015), our findings imply that keratins act upstream of, and help stabilize, lamins and lamin-associated proteins in the nuclear lamina. Furthermore, these findings offer a first potential mechanism for the hyperproliferation and increased susceptibility to colorectal cancer caused by K8 deletion in the colonic epithelium.

Weakening or loss of the connection between the nuclear lamina and the cytoplasmic cytoskeleton can be caused by the loss and/or mislocalization of lamins and/or LINC complex proteins, leading to the loss of anchoring sites for connecting the nuclear lamina to LINC complexes (Lombardi and Lammerding, 2011). As several LINC complex proteins, including SUN1 and SUN2, and the major lamin isoforms are downregulated in $\mathrm{K}^{-/-}$colonocytes, we can surmise that coupling of LINC complexes and the nuclear lamina may be compromised in these cells. While we were unable to probe nesprin-3 protein levels due to the lack of a good antibody, nesprin-3 gene expression was unaffected in $\mathrm{K}^{-/-}$colonocytes. Nonetheless, as SUN1 and SUN2 are downregulated in $\mathrm{K}^{-{ }^{--}}$colonocytes, and SUN proteins are required for correct localization of nesprin-3 at the ONM (Ketema et al., 2007), nesprin-3 is presumably displaced from the ONM. Furthermore, plectin, a cytolinker protein known to link nesprin-3 to vimentin and keratins (Wilhelmsen et al., 2005; Ketema et al., 2013; Almeida et al., 2015), is decreased in $\mathrm{K}^{-/-}$colonocytes, which supports the notion that the nuceloskeleton-cytoskeleton link is disrupted from the outside of the nucleus due to the loss of keratins and plectin. Our data in colonocytes support the findings reported for other cell types, that a continuous coupling between the cytoplasmic cytoskeleton and the nuclear lamina and the presence of laminassociated proteins, such as emerin, are important for maintaining nuclear integrity and mechanosignaling (Lombardi and Lammerding, 2011; Osmanagic-Myers et al., 2015). Due to the decrease or loss of many proteins along this axis, it is highly likely that nuclear integrity and mechanosignaling is weakened or disrupted in $\mathrm{K}^{-/-}$colonocytes, and that nuclei in these cells are more vulnerable to mechanical stress. This is supported by the findings that epidermal $\mathrm{K} 1 / \mathrm{K} 10$ loss in mice is associated with decreased levels of lamin A/C, emerin and SUN1 and a 
likely decoupling of the cytoskeleton and the nuclear lamina, leading to weakened nuclear integrity and premature loss of nuclei (Wallace et al., 2012). Similarly, mesenchymal vimentin IFs were recently shown to mechanically support nuclei, as the loss of vimentin caused increased nuclear rupture and DNA damage during cell migration (Patteson et al., 2019). Interestingly, in the present study, we observed increased nuclear translocation of the mechanosensor and transcriptional regulator YAP in $\mathrm{K}^{-/-}$compared to $\mathrm{K}^{+/+}$colonocytes, implying YAP activation by mechanical cues (Piccolo et al., 2014; Yui et al., 2018). In addition, K8/K18 siRNA-treated Caco-2 cells exhibit a robust nuclear YAP staining and decreased cytoplasmic YAP, compared to keratin-expressing cells. YAP activity was reported nonessential for intestinal homeostasis (Cai et al., 2010; Azzolin et al., 2014), however, upon DSS-induced colitis, YAP activity induced through mechanotransduction is indispensable for proliferation and regeneration in damaged colonic epithelium (Cai et al., 2010; Yui et al., 2018). YAP activation by mechanical cues involves the actomyosin cytoskeleton, Src family kinases and mechanical coupling of the cytoskeleton and nucleus (Elosegui-Artola et al., 2017; Ege et al., 2018), which would suggest that accumulation of nuclear YAP should be perturbed in $\mathrm{K} 8^{-}$ ${ }^{\prime}$ colonocytes, as these cells exhibit reduced LINC complex proteins (Fig. 6) and absent lateral and patchy apical F-actin (Toivola et al., 2004). As nuclear translocation of YAP is possible in $\mathrm{K}^{-/-}$colonocytes, the few remaining LINC proteins may form functional units which facilitate YAP translocation. Alternatively, cytoplasmic keratin filaments may be necessary for limiting nuclear translocation of YAP, which needs to be further investigated.

Mechanically-induced nuclear and transcriptionally active YAP promotes cell proliferation in many cell types, including epithelial cells (Piccolo et al., 2014). As YAP is important for repairing epithelium in the colon upon DSS-induced colitis (Cai et al., 2010; Yui et al., 2018), and $\mathrm{K}^{-/-}$mice develop colitis, it could be surmised that a YAP-induced regenerative state in $\mathrm{K}^{-/-}$colon epithelium contributes to the hyperproliferation observed in $\mathrm{K}^{-/-}$colon. The heightened regenerative and proliferative state in these mice is also evident from increased activation of IL-22 and STAT3 signaling (Misiorek et al., 2016). Little is known about the role of IFs or keratins in the regulation of YAP. However, the "rim-and-spoke" hypothesis for IFs (Quinlan et al., 2017), in which radial keratin spokes connecting the plasma membrane with the ONM could potentiate a mechanosensory function for keratins, thus fulfilling a similar or complementary function in mechanosensing for IFs similar to actin filaments and stress fibers.

Lamin B1 loss or upregulation have been associated with cellular senescence, either as causes or markers of senescence both in vitro (e.g. human fibroblasts or keratinocytes) (Shimi et al., 
2011; Barascu et al., 2012; Freund et al., 2012; Dreesen et al., 2013) and in vivo (e.g. mouse liver) (Freund et al., 2012; Dreesen et al., 2013). While decreased lamin B1 levels have been linked to senescence, it has also been linked to increased apoptosis (Harborth et al., 2001). Surprisingly, in disagreement with these findings, $\mathrm{K}^{-/-}$colonocytes exhibiting decreased lamin B1 levels show decreased senescence and apoptosis, and increased proliferation (Baribault et al., 1994; Habtezion et al., 2011; Lähdeniemi et al., 2017). Interestingly, the decreased senescence could be explained by the increased hyperphosphorylation of $\mathrm{pRb}$ in $\mathrm{K}^{-/-}$ colonocytes, as senescent cells are characterized by a lack of $\mathrm{pRb}$ phosphorylation (Stein et al., 1990; Gire and Dulic, 2015) and senescence can be bypassed by pRb inactivation (Sage et al., 2003).

In conclusion, we show in this study that simple epithelial keratin filaments offer support to lamins, LINC complex proteins and lamin-associated proteins in colonic epithelial cells, and that $\mathrm{K} 8$ loss leads to dramatically decreased levels of these proteins. Consequently, the coupling between the cytoskeleton and nuclear lamina may be disrupted. Inside the nucleus, increased $\mathrm{pRb}$ hyperphosphorylation likely deregulates cell cycle regulation and inhibits senescence, while nuclear translocation of YAP is increased, and collectively these changes likely contribute to the hyperproliferation in $\mathrm{K}^{-/}$colon. Our findings indicate a novel, colonocytespecific role for K8 in maintaining lamin levels and nuclear function, and that K8 may be a novel cytoskeletal factor involved in the mechanical coupling of the cytoskeleton and the nucleus.

\section{Materials and methods}

Experimental animals and sample collection. $\mathrm{K}^{+/+}, \mathrm{K}^{+/-}$and $\mathrm{K} 8^{-/-}$mice in the $\mathrm{FVB} / \mathrm{n}$ background (Baribault et al., 1994) were bred and genotyped by PCR as previously described (Baribault et al., 1994). All animals were housed at the Central Animal Laboratory of the University of Turku and treated according to animal study protocols (nos. 197/04.10.07/2013 and 3956/04.10.07/2016) approved by the State Provincial Office of South Finland. The mice were euthanized by $\mathrm{CO}_{2}$ inhalation and tissue samples were collected. Pieces of proximal colon (PC) and distal colon (DC) were collected for protein and RNA analysis, immunofluorescence staining and senescence detection. Colon epithelium was collected for protein and RNA analysis by scraping the luminal side of the colon with a chilled glass slide as previously described (Helenius et al., 2015). Ileum, liver, pancreas and lungs were collected for protein 
analysis. Protein analysis of colon epithelium and PC were performed on samples from 2-5 months old male and female mice unless otherwise stated. Pancreas were collected from 2-3 months old male and female mice, lungs were collected from 8-10.5 months old male and female mice, and liver and ileum were collected from 5.5-6.5 months old male and female mice. $K 8^{\text {flox/flox }}$ Villin-Cre mice in the $\mathrm{C} 57 \mathrm{BL} / 6$ background were of mixed gender and 4 months of age. LAP $2 \alpha$ mice were of the C57BL/6 background and 3-3.5 months of age.

Tamoxifen treatment of mice. A $15 \mathrm{mg} / \mathrm{ml}$ solution of tamoxifen (Sigma Aldrich, CA, USA) was prepared by dissolving $30 \mathrm{mg}$ tamoxifen in $0.2 \mathrm{ml}$ pure EtOH and then diluting it with 1.8 $\mathrm{ml}$ corn oil (Sigma Aldrich, CA, USA). Vehicle substance was prepared by mixing $0.2 \mathrm{ml}$ EtOH with $1.8 \mathrm{ml}$ corn oil. $\mathrm{K} 8^{\text {flox/flox }}$ Villin-Cre-ER ${ }^{\mathrm{T} 2}$ mice in the $\mathrm{C} 57 \mathrm{BL} / 6$ background received an intraperitoneal injection with $100 \mu \mathrm{l}$ of either tamoxifen (1.5 mg tamoxifen/mouse) or vehicle solution once per day for five consecutive days, whereafter the mice were kept for 3.5 weeks before they were sacrificed.

Antibiotic treatment of mice. Male and female $\mathrm{K}^{+/+}$and $\mathrm{K} 8^{-/-}$mice were treated with the broad-spectrum antibiotics vancomycin and imipenem (Hospira, IL, USA) administered via drinking water (68 mg/kg body weight/day of each antibiotic) for 8 weeks starting at 18-19 days of age, while control mice received normal drinking water. The drinking water (with or without antibiotics) was changed three times a week. Upon completion of the antibiotic treatment, the 2.5 months old mice were euthanized by $\mathrm{CO}_{2}$ inhalation, and colon epithelium was collected as described above.

DSS treatment of mice. $2 \%$ DSS (40 kDa, TdB Consultancy AB, Sweden) was administered in autoclaved water to 2.5 months old male BALB/c mice for 8 days. Upon completion of the DSS treatment, the mice were euthanized by $\mathrm{CO}_{2}$ inhalation and colon total lysate samples were collected.

Organoid culture. Colon organoids from $\mathrm{K}^{\text {flox/flox}} ; \mathrm{Villin}-\mathrm{Cre}-\mathrm{ER}^{\mathrm{T} 2}$ mice were isolated according to a modified previously described method (Stemcell Technologies, UK). Briefly, the mice were euthanized by $\mathrm{CO}_{2}$ inhalation and the colon was collected, cut open, washed with ice-cold PBS and incubated in $30 \mathrm{ml}$ of $5 \mathrm{mM}$ ethylenediaminetetraacetic acid (EDTA; $\mathrm{pH} \mathrm{8)}$ in PBS under rotation at RT for 20 minutes. Next, the colon was rinsed with PBS, followed by vigorous shaking by hand to mechanically detach the crypts. Isolated crypts were plated at approximately 2 crypts/ $\mu$ in Matrigel (Corning, NY, USA) domes diluted 1:1 with advanced DMEM/F12 media (Stemcell Technologies, UK), with $50 \mu$ domes per well. Once 
polymerized, $500 \mu 1$ of IntestiCult Organoid Growth Medium (Stemcell Technologies, UK) supplemented with $10 \mu \mathrm{M}$ Y-27632 (Adooq Bioscience, CA, USA) was added to each well and the colon organoids were cultured at $37^{\circ} \mathrm{C}$ in a $5 \% \mathrm{CO}_{2}$ atmosphere for 48 hours. After the initial 48-hour incubation with medium supplemented with Y-27632, the organoids were incubated with medium without Y-27632 and the medium was exchanged every 48 hours. Colon organoids were harvested for immunoblotting by dissolving the Matrigel with $500 \mu 1$ Gentle Cell Dissociation Reagent (Stemcell Technologies, UK) for 1 minute, whereafter the samples were centrifuged for 5 minutes at $2000 \mathrm{~g}$. The pellet was homogenized with homogenization buffer $(0.187 \mathrm{M}$ Tris- $\mathrm{HCl} \mathrm{pH} 6.8,3 \%$ SDS and $5 \mathrm{mM}$ EDTA) and protein concentrations were determined with a Pierce BCA protein assay kit (Thermo Fisher Scientific, Waltham, MA, USA).

Cell culture and sustained siRNA treatment with recovery. Caco-2 cells were grown on 10 cm cell culture plates in Dulbecco's Modified Eagle Medium (DMEM) containing $10 \%$ fetal calf serum, $2 \mathrm{mM}$ L-glutamine, 100 units $/ \mathrm{ml}$ penicillin and $100 \mu \mathrm{g} / \mathrm{ml}$ streptomycin. The cells were cultured at $37{ }^{\circ} \mathrm{C}$ in a $5 \% \mathrm{CO}_{2}$ atmosphere. For siRNA experiments, Caco-2 cells were plated on 24 - or 12 -well plates so that the cells were $20-30 \%$ confluent at the time of siRNA transfection.

siRNAs for human K8 (5'-GCCUCCUUCAUAGACAAGGUA(dTdT)-3') and K18 (5'GAGACUGGAGCCAUUACUUCA(dTdT)-3') and non-target siRNAs based on the K8 siRNA (K8 scramble siRNA; 5'-GUCGUAUAUGACACCGUACCA(dTdT)-3') and the K18 siRNA (K18 scramble siRNA; 5'-GUAACCAAUGUCGGCGAUACU(dTdT)-3') were designed in the lab and synthesized (siMAX siRNA, Eurofins Genomics, Ebersberg, Germany). Caco-2 cells were mock-transfected (all reagents except siRNA), transfected with K8 scramble siRNA and K18 scramble siRNA or transfected with K8 siRNA and K18 siRNA using Lipofectamine 2000 (Invitrogen, CA, USA) according to the manufacturer's instructions (Strnad et al., 2016). siRNA transfections were performed using 30 or 60 pmol of each siRNA and 1.5 or $3 \mu \mathrm{l}$ Lipofectamine 2000 per well in 24- or 12-well plates, respectively. For sustained keratin knockdown, siRNA transfections were repeated three times, followed by $72 \mathrm{~h}$ of incubation and subculture after each transfection, and by the end of the third 72-hour incubation samples were collected for protein analysis and immunofluorescence staining. Recovery of cells following siRNA treatment was achieved by incubating previously siRNA-treated cells three times for a 72-hour period which was followed by subculture. Samples were collected for protein analysis at the end of the third incubation period ( 9 days after the removal of siRNA). 
Immunoprecipitation. Caco-2 cells from two $10 \mathrm{~cm}$ cell culture plates were washed with PBS and harvested by scraping. Next, the cells were lysed in $1.5 \mathrm{ml}$ lysis buffer $(25 \mathrm{mM}$ Hepes (pH 8.0), $100 \mathrm{mM} \mathrm{NaCl}, 5 \mathrm{mM}$ EDTA, 0.5\% Triton X-100, $20 \mathrm{mM} \beta$-glycerophosphate, $20 \mathrm{mM}$ para-nitro-phenyl phosphate, $100 \mu \mathrm{M}$ ortovanadate, $0.5 \mathrm{mM}$ phenylmethylsulfonyl fluoride, $1 \mathrm{mM}$ dithiothreitol and complete mini protease inhibitor cocktail (Roche, Switzerland)), homogenized by passing the cells through a $23 \mathrm{G}$ needle 10 times and rested 45 minutes on ice. For immunoprecipitation, cell lysates were incubated with rabbit anti-lamin A (Abcam, UK) or mouse anti-K18 (L2A1; Professor Bishr Omary, Rutgers University) antibody (not added to control samples) under rotation at $4{ }^{\circ} \mathrm{C}$ overnight. $30 \mu$ of protein-A/G magnetic beads (Thermo Fisher Scientific, Waltham, MA, USA) were added to each sample and the samples were incubated under rotation at $4{ }^{\circ} \mathrm{C}$ for 20 minutes. The samples were washed three times in TEG buffer (20 mM Tris-HCl (pH 7.5), 1 mM EDTA, 10\% Glycerol, 0.5 mM phenylmethylsulfonyl fluoride, $1 \mathrm{mM}$ dithiothreitol and 1x complete mini protease cocktail (Roche, Switzerland)), dissolved in 3x Laemmli sample buffer and analyzed by SDS-PAGE and Western blot.

SDS-PAGE and Western blot. Protein samples were homogenized on ice in homogenization buffer (0.187 M Tris-HCl pH 6.8, 3 \% SDS and 5 mM EDTA) supplemented with 1x complete protease inhibitor cocktail (Roche, Switzerland) and $1 \mathrm{mM}$ phenylmethylsulfonyl fluoride. Sample protein concentrations were determined with a Pierce BCA protein assay kit (Thermo Fisher Scientific, Waltham, MA, USA) and the samples were normalized and diluted to $5 \mu \mathrm{g}$ protein $/ 10 \mu 1$ with $3 x$ Laemmli sample buffer (30\% glycerol, $3 \%$ SDS, $0.1875 \mathrm{M}$ Tris-HCl (pH 6.8), 0,015\% bromophenol blue and $3 \% \beta$-mercaptoethanol). The samples were separated on 6-10 \% SDS-polyacrylamide gels or 4-20\% Mini-PROTEAN TGX precast gradient gels (Bio-Rad, CA, USA) together with Precision Plus Protein Dual Color Standards (Bio-Rad, CA, USA), transferred to polyvinylidene fluoride membranes and analyzed by Western blot. Primary antibodies used for Western blotting were: rabbit anti- $\beta$-actin (Cell Signaling, MA, USA), mouse anti- $\beta$-tubulin (Sigma Aldrich, CA, USA), rabbit anti-Emerin (Abcam, UK), rabbit anti-GAPDH (Abcam, UK), rat anti-Hsc70 (Stressgen Bioreagents, MI, USA), rabbit anti-K18 275 (Professor John Eriksson, Finland), rat anti-K19 (Troma III; Developmental Studies Hybridoma Bank, IA, USA) rat anti-K8 (Troma I; Developmental Studies Hybridoma Bank, IA, USA), rabbit anti-Lamin A (Abcam, UK), rabbit anti-Lamin A (Robert Goldman, USA), rabbit anti-phospho Serine 22 - Lamin A/C (Cell Signaling, USA), mouse anti-Lamin A/C (Cell Signaling, MA, USA), rabbit anti-Lamin C (Robert Goldman, USA), mouse antiLamin B (Robert Goldman, USA), rabbit anti-Lamin B1 (Abcam, UK), mouse anti-Lamin B2 
(Robert Goldman, USA), mouse anti-LAP2 $\alpha$ (Roland Foisner, Austria), rabbit anti-Plectin (Gerhard Wiche, Austria), rabbit anti-pRb (Abcam, UK), rabbit anti-phospho-pRb (phosphoSer 807 and phospho-Ser 811; Cell Signaling, MA, USA), rabbit anti-SUN1 (Abcam, UK), rabbit anti-SUN2 (Abcam, UK) and rabbit anti-YAP (Cell Signaling, MA, USA). Secondary antibodies used for Western blotting were anti-rabbit Alexa Fluor 488/680/800 (Invitrogen, CA, USA), anti-rat Alexa Fluor 488/680 (Invitrogen, CA, USA), anti-mouse Alexa Fluor 488/800 (Invitrogen, CA, USA), anti-rabbit IgG-horseradish peroxidase (HRP) (Promega, WI, USA), anti-rat IgG-HRP (GE Healthcare, UK), anti-rat IgG-HRP (Cell signaling, US) and anti-mouse IgG-HRP (GE Healthcare, UK). HRP-labeled proteins were detected with Amersham ECL Western Blotting Detection Reagent (GE Healthcare, UK) or Western Lightning Plus-ECL (Perkin Elmer, MA, USA) and visualized either on SUPER RX X-ray films (Fuji Corporation, Tokyo, Japan) or using an iBright FL1000 imaging system (Invitrogen, CA, USA). Fluorescently labeled proteins were detected using an iBright FL1000 imaging system (Invitrogen, CA, USA). The Western blot results were quantified using ImageJ software (National Institutes of Health, MD, USA) as previously described (Schneider et al., 2012) and normalized to loading controls (Hsc70 or $\beta$-tubulin).

RNA isolation and quantitative RT-PCR. Total lysates of colon tissue were obtained by collecting and combining pieces of PC and DC from 2-5 months old $\mathrm{K}^{+/+}$and $\mathrm{K}^{-/-}$male and female mice. The samples were homogenized with a TissueRuptor homogenizer (Qiagen, Germany) and RNA was isolated using a Nucleospin RNA isolation kit (Macherey-Nagel, Germany). Agarose gel analysis was used to assess RNA quality. cDNA was synthesized from $1 \mu \mathrm{g}$ of each RNA sample using Oligo(dT) 15 Primer (Promega) and M-MLV Reverse Transcriptase (RNase H Minus, Point Mutant; Promega). Quantitative (q)RT-PCR reactions for target genes were prepared using specific primer (Oligomer, Helsinki, Finland) and probe (Universal probe library, Roche, Basel, Switzerland) combinations (Supplemental Table S1). The target genes were amplified and detected with an Applied Biosystems QuantStudio 3 RealTime PCR System (Thermo Fisher Scientific) and the gene expression levels were normalized to $\beta$-Actin. Each cDNA was amplified in triplicates.

Cryosectioning, fixation and immunofluorescence staining. Pieces of PC and DC from 2-5 months old $\mathrm{K}^{+/+}$and $\mathrm{K}^{-/-}$male and female mice were embedded in Tissue-Tek O.C.T compound (Sakura Finetek Europe B.V., Alphen aan den Rijn, The Netherlands) and frozen. The samples were sectioned into $6 \mu \mathrm{m}$ thick cross sections with a Leica CM3050 S Research Cryostat (Leica Microsystems, Wetzlar, Germany), mounted on microscope slides and fixed 
with $1 \%$ PFA in PBS, pH 7.4 (Sigma Aldrich, CA, USA) at RT for 10 minutes. Caco-2 cells were cultured on cover slips and fixed similarily with $1 \%$ PFA at RT for 10 minutes. The fixed tissue sections and cell samples were stained as previously described ( $\mathrm{Ku}$ et al., 2004). The primary antibodies used for immunofluorescence staining were rabbit anti-Lamin A (Abcam, UK), mouse anti-Lamin A/C (Cell Signaling, MA, USA), rabbit anti-Lamin B1 (Abcam, UK), rabbit anti-Myeloperoxidase (MPO; Thermo Fisher Scientific), rat anti-K8 (Troma I, Developmental Hybridoma Bank, NIH, MD; USA), and rabbit anti-YAP (Cell Signaling, MA, USA). The fluorescent secondary antibodies used were anti-mouse Alexa Fluor 488, anti-rabbit Alexa Fluor 488, anti-rat Alexa Fluor 568, anti-rabbit Alexa Fluor 647 (Invitrogen, CA, USA). Draq5 (Cell Signaling, MA, USA) or DAPI (Invitrogen, CA, USA) was used as a nuclear marker. The samples were mounted with ProLong Gold Antifade (Thermo Fisher Scientific). Samples were visualized and imaged at room temperature using a Leica TCS SP5 Matrix confocal microscope (Leica Microsystems) equipped with a 63x Leica PL Apochromat/1.32 oil objective (Leica Microsystems) or a 100x Leica PL Fluotar/1.3 oil objective (Leica Microsystems) using Leica LAS software or a 3i Marianas Spinning disk confocal microscope (Intelligent Imaging Innovations) equipped with a Hamamatsu sCMOS Orca Flash4 v2 C11440-22CU camera (Hamamatsu Photonics, Japan) and a 20x Zeiss Plan-Apochromat/0.8 dry objective (Carl Zeiss AG, Germany) or a 63x Zeiss Plan-Apochromat/1.4 oil objective (Carl Zeiss AG) using Slidebook 6 software. Identical microscopy settings were applied to all samples within one imaging experiment. Images were processed using ImageJ/Fiji and Adobe Photoshop (Adobe, CA, USA) software (Schindelin et al., 2012; Schneider et al., 2012).

Senescence-associated $\boldsymbol{\beta}$-galactosidase staining. Senescent cells in mouse colon were detected using a Senescence $\beta$-Galactosidase Staining Kit (Cell Signaling Technology). Briefly, 10-11.5 months old female $\mathrm{K}^{+/+}$and $\mathrm{K}^{-/-}$mice were sacrificed, and PC and DC samples were collected, embedded in Tissue-Tek O.C.T compound and frozen. $4 \mu \mathrm{m}$ thick sections of PC and DC were produced using a Leica CM3050 S Research Cryostat (Leica Microsystems) and mounted onto microscope slides. The samples were fixed, washed twice with PBS and covered with staining solution. The samples were incubated for 16-18 hours in a dry incubator $\left(\right.$ no $\left.\mathrm{CO}_{2}\right)$, mounted with mowiol and imaged with a Pannoramic Midi FL slide scanner (3DHISTECH, Budapest, Hungary). ImageJ software was used to quantify the percentage of senescent cells by dividing the area of senescence-associated $\beta$-galactosidase-positive cells with the total area of the tissue sections. 
Statistical analysis. All quantified Western blot results were statistically analyzed using one way-ANOVA and t-test in GraphPad Prism 5 (GraphPad Software, CA, USA). The results show the mean \pm standard deviation (SD) with significant differences shown as $*=\mathrm{p}<0.05, * *=\mathrm{p}$ $<0.01$ or $* * *=\mathrm{p}<0.001$.

\section{Acknowledgments}

We thank Prof. Gerhard Wiche (Max Perutz Labs, Medical University of Vienna) for the kind donation of the plectin antibody, Assistant professor Pekka Taimen (University of Turku) for the $\mathrm{ppRb}$ antibodies and fruitful discussions, Assistant professor Keijo Viiri (University of Tampere) for the Cre-villin mouse strains, and Petra Fichtinger for help with the LAP2 $\alpha$ mice (Max Perutz Labs, Medical University of Vienna). We are grateful to all the other members of the Toivola laboratory, especially Frank Weckström, Theresia Jansson, Molly Feiring and Taina Heikkilä (Biosciences/Cell Biology, Faculty of Science and Engineering, Åbo Akademi University; $\AA \mathrm{AU})$, and to members of John Eriksson's laboratory, especially Elin Torvaldson and Josef Gullmets (Turku Bioscience Centre, University of Turku and $\AA$ AU, and Biosciences/Cell Biology, ÅAU) for fruitful discussions. Imaging was performed at the Cell Imaging and Cytometry Core at Turku Bioscience Centre (University of Turku and $\AA A U$ ) and Biocenter Finland. This work was financed by the Academy of Finland 140759/126161 (DMT), Sigrid Juselius Foundation (DMT), Turku Doctoral Programme in Molecular Biosciences at ÅAU (CGAS, JHN), Medicinska Understödsföreningen Liv och Hälsa Foundation (DMT, JHN, CGAS), EU FP7 IRG (DMT), ÅAU Center of Excellence of Cell Stress and Molecular Aging (DMT), The Swedish Cultural Foundation in Finland (JHN, CGAS), Agneta och CarlErik Olins foundation (JHN, CGAS), Victoria foundation (CGAS, JHN), K. Albin Johansson foundation (CGAS, JHN), Kommersrådet Otto A. Malms Donationsfond (JHN) and Waldemar von Frenckells foundation (JHN), the EuroCellNet COST Action (CA15214) (DMT, RF), NIH PO1 GM096971 (RDG) and NIH RO106023 (RDG).

\section{Author contributions}

CGAS, JHN, KMR, CBHM, SAA, RDG and DMT conceived and/or designed the experiments; CGAS, JHN, CBH, KR, RF performed the experiments; CGAS, JHN, CBH and DMT analyzed the data; CGAS, JHN and DMT composed the manuscript; CGAS, JHN, DMT, CBH, RF edited the manuscript; CGAS and JHN contributed equally to this manuscript. 


\section{Additional information}

Conflict of interest, the authors declare no competing financial interest.

\section{References}

Almeida, F.V., Walko, G., McMillan, J.R., McGrath, J.A., Wiche, G., Barber, A.H., and Connelly, J.T. (2015). The cytolinker plectin regulates nuclear mechanotransduction in keratinocytes. J Cell Sci 128, 4475-4486.

Ameen, N.A., Figueroa, Y., and Salas, P.J. (2001). Anomalous apical plasma membrane phenotype in CK8-deficient mice indicates a novel role for intermediate filaments in the polarization of simple epithelia. J Cell Sci 114, 563-575.

Asghar, M.N., Priyamvada, S., Nyström, J.H., Anbazhagan, A.N., Dudeja, P.K., and Toivola, D.M. (2016). Keratin 8 knockdown leads to loss of the chloride transporter DRA in the colon. Am J Physiol Gastrointest Liver Physiol 310, G1147-1154.

Asghar, M.N., Silvander, J.S., Helenius, T.O., Lähdeniemi, I.A., Alam, C., Fortelius, L.E., Holmsten, R.O., and Toivola, D.M. (2015). The amount of keratins matters for stress protection of the colonic epithelium. PLoS One 10, e0127436.

Azzolin, L., Panciera, T., Soligo, S., Enzo, E., Bicciato, S., Dupont, S., Bresolin, S., Frasson, C., Basso, G., Guzzardo, V., Fassina, A., Cordenonsi, M., and Piccolo, S. (2014). YAP/TAZ incorporation in the beta-catenin destruction complex orchestrates the Wnt response. Cell 158, 157-170.

Barascu, A., Le Chalony, C., Pennarun, G., Genet, D., Imam, N., Lopez, B., and Bertrand, P. (2012). Oxidative stress induces an ATM-independent senescence pathway through p38 MAPK-mediated lamin B1 accumulation. EMBO J 31, 1080-1094.

Baribault, H., Penner, J., Iozzo, R.V., and Wilson-Heiner, M. (1994). Colorectal hyperplasia and inflammation in keratin 8-deficient FVB/N mice. Genes Dev 8, 2964-2973.

Belt, E.J., Fijneman, R.J., van den Berg, E.G., Bril, H., Delis-van Diemen, P.M., Tijssen, M., van Essen, H.F., de Lange-de Klerk, E.S., Belien, J.A., Stockmann, H.B., Meijer, S., and Meijer, G.A. (2011). Loss of lamin A/C expression in stage II and III colon cancer is associated with disease recurrence. Eur J Cancer 47, 1837-1845.

Brady, G.F., Kwan, R., Bragazzi Cunha, J., Elenbaas, J.S., and Omary, M.B. (2018). Lamins and Lamin-Associated Proteins in Gastrointestinal Health and Disease. Gastroenterology 154, 1602-1619 e1601.

Cai, J., Zhang, N., Zheng, Y., de Wilde, R.F., Maitra, A., and Pan, D. (2010). The Hippo signaling pathway restricts the oncogenic potential of an intestinal regeneration program. Genes Dev 24, 2383-2388.

Coulombe, P.A., Hutton, M.E., Letai, A., Hebert, A., Paller, A.S., and Fuchs, E. (1991). Point mutations in human keratin 14 genes of epidermolysis bullosa simplex patients: genetic and functional analyses. Cell 66, 1301-1311.

Coulombe, P.A., and Omary, M.B. (2002). 'Hard' and 'soft' principles defining the structure, function and regulation of keratin intermediate filaments. Curr Opin Cell Biol 14, 110-122.

Crisp, M., Liu, Q., Roux, K., Rattner, J.B., Shanahan, C., Burke, B., Stahl, P.D., and Hodzic, D. (2006). Coupling of the nucleus and cytoplasm: role of the LINC complex. J Cell Biol 172, 41-53.

de Leeuw, R., Gruenbaum, Y., and Medalia, O. (2018). Nuclear Lamins: Thin Filaments with Major Functions. Trends Cell Biol 28, 34-45.

Dechat, T., Adam, S.A., Taimen, P., Shimi, T., and Goldman, R.D. (2010). Nuclear lamins. Cold Spring Harb Perspect Biol 2, a000547. 
Dechat, T., Korbei, B., Vaughan, O.A., Vlcek, S., Hutchison, C.J., and Foisner, R. (2000). Lamina-associated polypeptide 2alpha binds intranuclear A-type lamins. J Cell Sci 113 Pt 19, 3473-3484.

Dechat, T., Pfleghaar, K., Sengupta, K., Shimi, T., Shumaker, D.K., Solimando, L., and Goldman, R.D. (2008). Nuclear lamins: major factors in the structural organization and function of the nucleus and chromatin. Genes Dev 22, 832-853.

Dreesen, O., Chojnowski, A., Ong, P.F., Zhao, T.Y., Common, J.E., Lunny, D., Lane, E.B., Lee, S.J., Vardy, L.A., Stewart, C.L., and Colman, A. (2013). Lamin B1 fluctuations have differential effects on cellular proliferation and senescence. J Cell Biol 200, 605-617.

Ege, N., Dowbaj, A.M., Jiang, M., Howell, M., Hooper, S., Foster, C., Jenkins, R.P., and Sahai, E. (2018). Quantitative Analysis Reveals that Actin and Src-Family Kinases Regulate Nuclear YAP1 and Its Export. Cell Syst 6, 692-708 e613.

Elosegui-Artola, A., Andreu, I., Beedle, A.E.M., Lezamiz, A., Uroz, M., Kosmalska, A.J., Oria, R., Kechagia, J.Z., Rico-Lastres, P., Le Roux, A.L., Shanahan, C.M., Trepat, X., Navajas, D., Garcia-Manyes, S., and Roca-Cusachs, P. (2017). Force Triggers YAP Nuclear Entry by Regulating Transport across Nuclear Pores. Cell 171, 1397-1410 e1314.

Escobar-Hoyos, L.F., Shah, R., Roa-Pena, L., Vanner, E.A., Najafian, N., Banach, A., Nielsen, E., Al-Khalil, R., Akalin, A., Talmage, D., and Shroyer, K.R. (2015). Keratin-17 Promotes p27KIP1 Nuclear Export and Degradation and Offers Potential Prognostic Utility. Cancer Res 75, 3650-3662.

Freund, A., Laberge, R.M., Demaria, M., and Campisi, J. (2012). Lamin B1 loss is a senescence-associated biomarker. Mol Biol Cell 23, 2066-2075.

Gesson, K., Vidak, S., and Foisner, R. (2014). Lamina-associated polypeptide (LAP)2alpha and nucleoplasmic lamins in adult stem cell regulation and disease. Semin Cell Dev Biol 29, 116124.

Gire, V., and Dulic, V. (2015). Senescence from G2 arrest, revisited. Cell Cycle 14, 297-304. Habtezion, A., Toivola, D.M., Asghar, M.N., Kronmal, G.S., Brooks, J.D., Butcher, E.C., and Omary, M.B. (2011). Absence of keratin 8 confers a paradoxical microflora-dependent resistance to apoptosis in the colon. Proc Natl Acad Sci U S A 108, 1445-1450.

Habtezion, A., Toivola, D.M., Butcher, E.C., and Omary, M.B. (2005). Keratin-8-deficient mice develop chronic spontaneous Th2 colitis amenable to antibiotic treatment. J Cell Sci 118, 1971-1980.

Harborth, J., Elbashir, S.M., Bechert, K., Tuschl, T., and Weber, K. (2001). Identification of essential genes in cultured mammalian cells using small interfering RNAs. J Cell Sci 114, 45574565 .

Helenius, T.O., Misiorek, J.O., Nyström, J.H., Fortelius, L.E., Habtezion, A., Liao, J., Asghar, M.N., Zhang, H., Azhar, S., Omary, M.B., and Toivola, D.M. (2015). Keratin 8 absence downregulates colonocyte HMGCS2 and modulates colonic ketogenesis and energy metabolism. Mol Biol Cell 26, 2298-2310.

Hobbs, R.P., DePianto, D.J., Jacob, J.T., Han, M.C., Chung, B.M., Batazzi, A.S., Poll, B.G., Guo, Y., Han, J., Ong, S., Zheng, W., Taube, J.M., Cihakova, D., Wan, F., and Coulombe, P.A. (2015). Keratin-dependent regulation of Aire and gene expression in skin tumor keratinocytes. Nat Genet 47, 933-938.

Ketema, M., Kreft, M., Secades, P., Janssen, H., and Sonnenberg, A. (2013). Nesprin-3 connects plectin and vimentin to the nuclear envelope of Sertoli cells but is not required for Sertoli cell function in spermatogenesis. Mol Biol Cell 24, 2454-2466.

Ketema, M., Wilhelmsen, K., Kuikman, I., Janssen, H., Hodzic, D., and Sonnenberg, A. (2007). Requirements for the localization of nesprin-3 at the nuclear envelope and its interaction with plectin. J Cell Sci 120, 3384-3394. 
Ku, N.O., Darling, J.M., Krams, S.M., Esquivel, C.O., Keeffe, E.B., Sibley, R.K., Lee, Y.M., Wright, T.L., and Omary, M.B. (2003). Keratin 8 and 18 mutations are risk factors for developing liver disease of multiple etiologies. Proc Natl Acad Sci U S A 100, 6063-6068.

Lee, C.H., Kim, M.S., Chung, B.M., Leahy, D.J., and Coulombe, P.A. (2012). Structural basis for heteromeric assembly and perinuclear organization of keratin filaments. Nat Struct Mol Biol 19, 707-715.

Libotte, T., Zaim, H., Abraham, S., Padmakumar, V.C., Schneider, M., Lu, W., Munck, M., Hutchison, C., Wehnert, M., Fahrenkrog, B., Sauder, U., Aebi, U., Noegel, A.A., and Karakesisoglou, I. (2005). Lamin A/C-dependent localization of Nesprin-2, a giant scaffolder at the nuclear envelope. Mol Biol Cell 16, 3411-3424.

Liu, C., Liu, E.D., Meng, Y.X., Dong, X.M., Bi, Y.L., Wu, H.W., Jin, Y.C., Zhao, K., Li, J.J., Yu, M., Zhan, Y.Q., Chen, H., Ge, C.H., Yang, X.M., and Li, C.Y. (2017). Keratin 8 reduces colonic permeability and maintains gut microbiota homeostasis, protecting against colitis and colitis-associated tumorigenesis. Oncotarget 8, 96774-96790.

Lombardi, M.L., and Lammerding, J. (2011). Keeping the LINC: the importance of nucleocytoskeletal coupling in intracellular force transmission and cellular function. Biochem Soc Trans 39, 1729-1734.

Lähdeniemi, I.A.K., Misiorek, J.O., Antila, C.J.M., Landor, S.K., Stenvall, C.A., Fortelius, L.E., Bergström, L.K., Sahlgren, C., and Toivola, D.M. (2017). Keratins regulate colonic epithelial cell differentiation through the Notch1 signalling pathway. Cell Death Differ 24, 984996.

Markiewicz, E., Dechat, T., Foisner, R., Quinlan, R.A., and Hutchison, C.J. (2002). Lamin A/C binding protein LAP2alpha is required for nuclear anchorage of retinoblastoma protein. Mol Biol Cell 13, 4401-4413.

Misiorek, J.O., Lahdeniemi, I.A.K., Nystrom, J.H., Paramonov, V.M., Gullmets, J.A., Saarento, H., Rivero-Muller, A., Husoy, T., Taimen, P., and Toivola, D.M. (2016). Keratin 8-deletion induced colitis predisposes to murine colorectal cancer enforced by the inflammasome and IL22 pathway. Carcinogenesis 37, 777-786.

Muchir, A., Wu, W., and Worman, H.J. (2009). Reduced expression of A-type lamins and emerin activates extracellular signal-regulated kinase in cultured cells. Biochim Biophys Acta 1792, 75-81.

Naetar, N., Ferraioli, S., and Foisner, R. (2017). Lamins in the nuclear interior - life outside the lamina. J Cell Sci 130, 2087-2096.

Naetar, N., Korbei, B., Kozlov, S., Kerenyi, M.A., Dorner, D., Kral, R., Gotic, I., Fuchs, P., Cohen, T.V., Bittner, R., Stewart, C.L., and Foisner, R. (2008). Loss of nucleoplasmic LAP2alpha-lamin A complexes causes erythroid and epidermal progenitor hyperproliferation. Nat Cell Biol 10, 1341-1348.

Omary, M.B. (2017). Intermediate filament proteins of digestive organs: physiology and pathophysiology. Am J Physiol Gastrointest Liver Physiol 312, G628-G634.

Osmanagic-Myers, S., Dechat, T., and Foisner, R. (2015). Lamins at the crossroads of mechanosignaling. Genes Dev 29, 225-237.

Patteson, A.E., Vahabikashi, A., Pogoda, K., Adam, S.A., Mandal, K., Kittisopikul, M., Sivagurunathan, S., Goldman, A., Goldman, R.D., and Janmey, P.A. (2019). Vimentin protects cells against nuclear rupture and DNA damage during migration. J Cell Biol.

Piccolo, S., Dupont, S., and Cordenonsi, M. (2014). The biology of YAP/TAZ: hippo signaling and beyond. Physiol Rev 94, 1287-1312.

Quinlan, R.A., Schwarz, N., Windoffer, R., Richardson, C., Hawkins, T., Broussard, J.A., Green, K.J., and Leube, R.E. (2017). A rim-and-spoke hypothesis to explain the biomechanical roles for cytoplasmic intermediate filament networks. J Cell Sci 130, 3437-3445. 
Sage, J., Miller, A.L., Perez-Mancera, P.A., Wysocki, J.M., and Jacks, T. (2003). Acute mutation of retinoblastoma gene function is sufficient for cell cycle re-entry. Nature 424, $223-$ 228.

Schindelin, J., Arganda-Carreras, I., Frise, E., Kaynig, V., Longair, M., Pietzsch, T., Preibisch, S., Rueden, C., Saalfeld, S., Schmid, B., Tinevez, J.Y., White, D.J., Hartenstein, V., Eliceiri, K., Tomancak, P., and Cardona, A. (2012). Fiji: an open-source platform for biological-image analysis. Nat Methods 9, 676-682.

Schneider, C.A., Rasband, W.S., and Eliceiri, K.W. (2012). NIH Image to ImageJ: 25 years of image analysis. Nat Methods 9, 671-675.

Schweizer, J., Bowden, P.E., Coulombe, P.A., Langbein, L., Lane, E.B., Magin, T.M., Maltais, L., Omary, M.B., Parry, D.A., Rogers, M.A., and Wright, M.W. (2006). New consensus nomenclature for mammalian keratins. J Cell Biol 174, 169-174.

Shimi, T., Butin-Israeli, V., Adam, S.A., Hamanaka, R.B., Goldman, A.E., Lucas, C.A., Shumaker, D.K., Kosak, S.T., Chandel, N.S., and Goldman, R.D. (2011). The role of nuclear lamin B1 in cell proliferation and senescence. Genes Dev 25, 2579-2593.

Stein, G.H., Beeson, M., and Gordon, L. (1990). Failure to phosphorylate the retinoblastoma gene product in senescent human fibroblasts. Science 249, 666-669.

Strnad, P., Guldiken, N., Helenius, T.O., Misiorek, J.O., Nystrom, J.H., Lahdeniemi, I.A., Silvander, J.S., Kuscuoglu, D., and Toivola, D.M. (2016). Simple Epithelial Keratins. Methods Enzymol 568, 351-388.

Tapley, E.C., and Starr, D.A. (2013). Connecting the nucleus to the cytoskeleton by SUNKASH bridges across the nuclear envelope. Curr Opin Cell Biol 25, 57-62.

Toivola, D.M., Boor, P., Alam, C., and Strnad, P. (2015). Keratins in health and disease. Curr Opin Cell Biol 32, 73-81.

Toivola, D.M., Krishnan, S., Binder, H.J., Singh, S.K., and Omary, M.B. (2004). Keratins modulate colonocyte electrolyte transport via protein mistargeting. J Cell Biol 164, 911-921.

Toivola, D.M., Tao, G.Z., Habtezion, A., Liao, J., and Omary, M.B. (2005). Cellular integrity plus: organelle-related and protein-targeting functions of intermediate filaments. Trends Cell Biol 15, 608-617.

Wagner, N., and Krohne, G. (2007). LEM-Domain proteins: new insights into lamin-interacting proteins. Int Rev Cytol 261, 1-46.

Wallace, L., Roberts-Thompson, L., and Reichelt, J. (2012). Deletion of K1/K10 does not impair epidermal stratification but affects desmosomal structure and nuclear integrity. J Cell Sci $125,1750-1758$.

Wang, A.S., Kozlov, S.V., Stewart, C.L., and Horn, H.F. (2015). Tissue specific loss of A-type lamins in the gastrointestinal epithelium can enhance polyp size. Differentiation 89, 11-21.

Vaughan, A., Alvarez-Reyes, M., Bridger, J.M., Broers, J.L., Ramaekers, F.C., Wehnert, M., Morris, G.E., Whitfield, W.G.F., and Hutchison, C.J. (2001). Both emerin and lamin C depend on lamin A for localization at the nuclear envelope. J Cell Sci 114, 2577-2590.

Weinberg, R.A. (1995). The retinoblastoma protein and cell cycle control. Cell 81, 323-330.

Vidak, S., Georgiou, K., Fichtinger, P., Naetar, N., Dechat, T., and Foisner, R. (2018). Nucleoplasmic lamins define growth-regulating functions of lamina-associated polypeptide 2alpha in progeria cells. J Cell Sci 131.

Wilhelmsen, K., Litjens, S.H., Kuikman, I., Tshimbalanga, N., Janssen, H., van den Bout, I., Raymond, K., and Sonnenberg, A. (2005). Nesprin-3, a novel outer nuclear membrane protein, associates with the cytoskeletal linker protein plectin. J Cell Biol 171, 799-810.

Wilson, K.L., and Foisner, R. (2010). Lamin-binding Proteins. Cold Spring Harb Perspect Biol 2, a000554.

Worman, H.J. (2012). Nuclear lamins and laminopathies. J Pathol 226, 316-325. 
bioRxiv preprint doi: https://doi.org/10.1101/2020.06.22.164467; this version posted June 22, 2020. The copyright holder for this preprint (which was not certified by peer review) is the author/funder, who has granted bioRxiv a license to display the preprint in perpetuity. It is made available under aCC-BY-NC-ND 4.0 International license.

Yang, H.S., and Hinds, P.W. (2007). pRb-mediated control of epithelial cell proliferation and Indian hedgehog expression in mouse intestinal development. BMC Dev Biol 7, 6.

Yui, S., Azzolin, L., Maimets, M., Pedersen, M.T., Fordham, R.P., Hansen, S.L., Larsen, H.L., Guiu, J., Alves, M.R.P., Rundsten, C.F., Johansen, J.V., Li, Y., Madsen, C.D., Nakamura, T., Watanabe, M., Nielsen, O.H., Schweiger, P.J., Piccolo, S., and Jensen, K.B. (2018). YAP/TAZDependent Reprogramming of Colonic Epithelium Links ECM Remodeling to Tissue Regeneration. Cell Stem Cell 22, 35-49 e37.

Zhou, Q., Toivola, D.M., Feng, N., Greenberg, H.B., Franke, W.W., and Omary, M.B. (2003). Keratin 20 helps maintain intermediate filament organization in intestinal epithelia. Mol Biol Cell 14, 2959-2971. 


\section{FIGURES AND LEGENDS}

A.

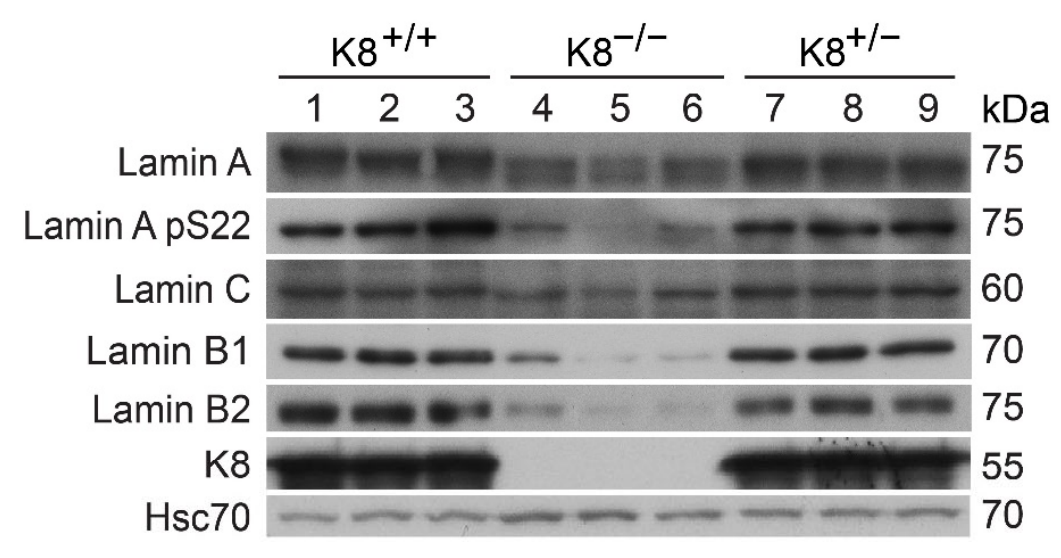

D.

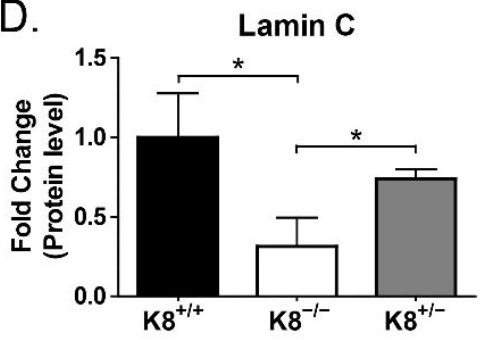

B.

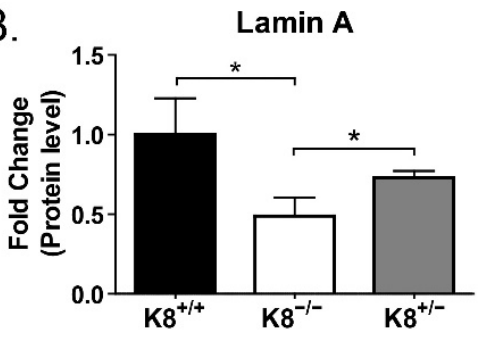

C.

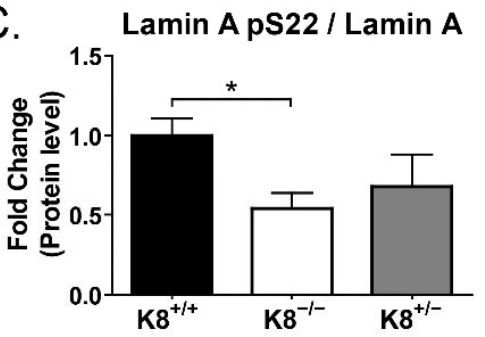

F.

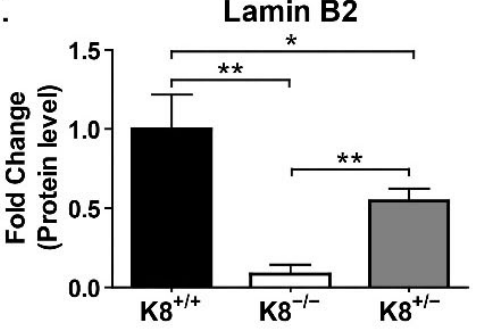

Figure 1. Lamins A, B1, B2 and $\mathrm{C}$ are downregulated in isolated $\mathrm{K} 8^{-/}$mouse colon epithelial cells. A) Lysates of crudely isolated colon epithelium from $\mathrm{K}^{+/+}$(lanes 1-3), $\mathrm{K}^{-/-}$(lanes 4-6) and $\mathrm{K}^{+/-}$(lanes 7-9) mice $(\mathrm{n}=3)$ were immunoblotted for lamins $\mathrm{A}$, lamin $\mathrm{A} \mathrm{pS22}$, lamin $\mathrm{C}$, lamin B1, lamin B2, and K8. Hsc70 was used as a loading control. B-F) The immunoblots in A) were quantified and normalized to Hsc70 (or lamin A for lamin A pS22) protein levels. The results are representative of 2 other similar sets of mice and represent the mean $(n=3)$ protein quantity \pm SD with significant differences shown as $*=p<0.05, * *=p<0.01$ and $* * *=p<$ 0.001 . 


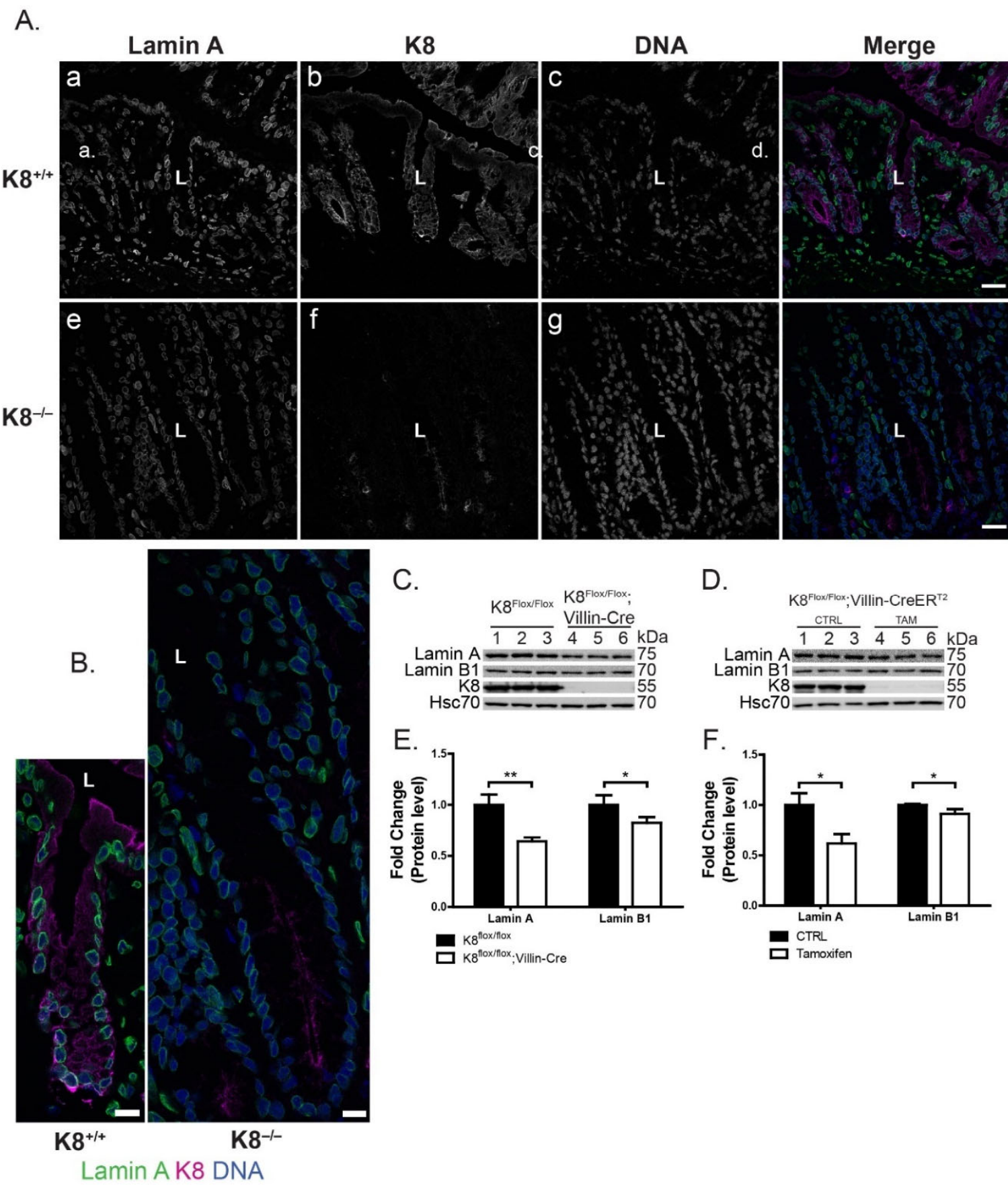

Figure 2. Loss of lamin A occurs only in colon crypt epithelial cells, and intestine-specific $\mathrm{K} 8^{-}$ ${ }^{1-}$ mouse colon epithelial cells have decreased lamin protein levels. A-B) $\mathrm{K}^{+/+}$and $\mathrm{K}^{-/-}$mouse colon tissue cryosections were immunostained for lamin A (green), K8 (magenta) and DNA (DRAQ5, blue). The individual images in A) and the enlarged merged pictures of crypts in B) show the colon epithelial cell-specific lamin A loss in the long and hyperproliferating crypts in the $\mathrm{K} 8^{-/-}$colon. Scale bars $=25 \mu \mathrm{m}(\mathrm{A})$ and $10 \mu \mathrm{m}(\mathrm{B})$. C-F) Lysates of crudely isolated colon epithelium from control $\mathrm{K} 8^{\text {flox/flox }}$ (lanes 1-3 in $\mathrm{C}$ ) and $\mathrm{K} 8^{\text {flox/flox; }}$ Villin-Cre (endogenous $\mathrm{K} 8$ knockdown; lanes 4-6 in C) mice and non-treated (control; CTRL; lanes 1-3 in D), and tamoxifen (TAM)-treated K8 $8^{\text {flox/flox; }}$ Villin-Cre-ER ${ }^{\mathrm{T} 2}$ (induced $\mathrm{K} 8$ knockdown; lanes 4-6 in D) mice were immunoblotted for lamins $\mathrm{A}$ and $\mathrm{B} 1$ and $\mathrm{K} 8$. The immunoblots were quantified and normalized to Hsc70 protein levels (loading control). The results represent the mean $(n=3)$ protein quantity $\pm \mathrm{SD}$ with significant differences shown as $*=p<0.05$ and $* *=p<0.01$. 


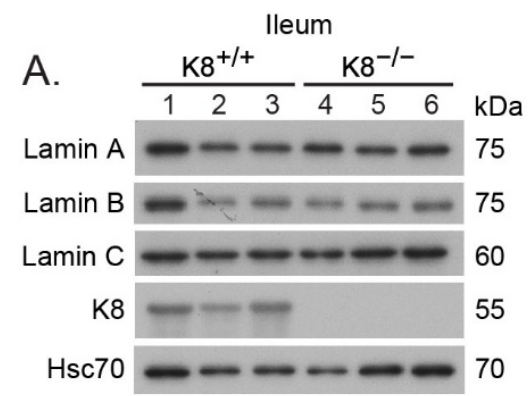

B.
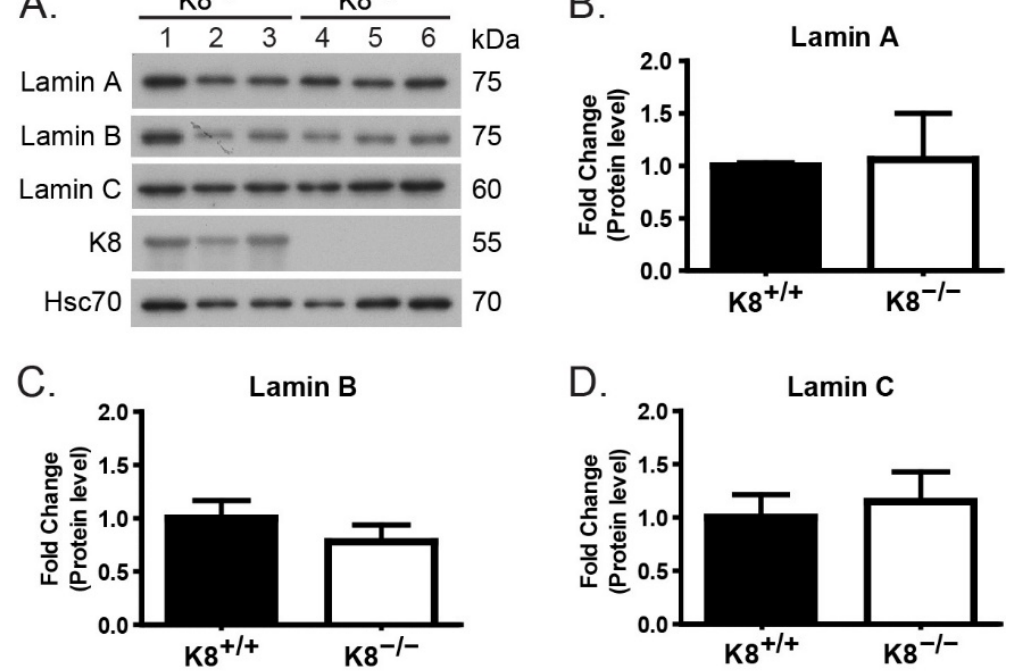

Figure 3. Lamin protein levels are comparable in $\mathrm{K}^{+/+}$and $\mathrm{K}^{-/-}$mouse ileum. A) Total lysates of ileum from $\mathrm{K}^{+/+}$(lanes 1-3) and $\mathrm{K}^{-/-}$(lanes 4-6) mice were immunoblotted for lamins $\mathrm{A}$, $\mathrm{B}$ and $\mathrm{C}$ and $\mathrm{K} 8$. Hsc70 was used as a loading control. B-D) The immunoblots were quantified and normalized to Hsc70 protein levels. The results represent the mean $(\mathrm{n}=3)$ protein quantity \pm SD. No statistically significant differences were observed between $\mathrm{K} 8^{+/+}$and $\mathrm{K}^{-/-}$samples. 
A.

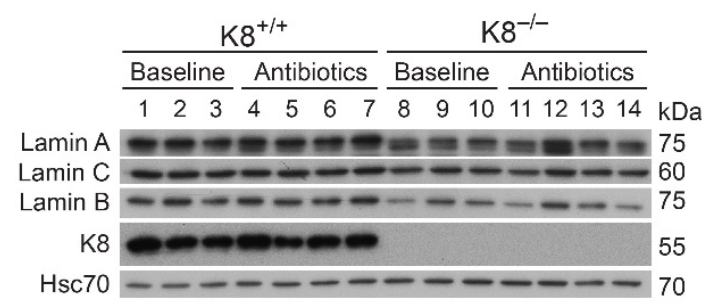

C.

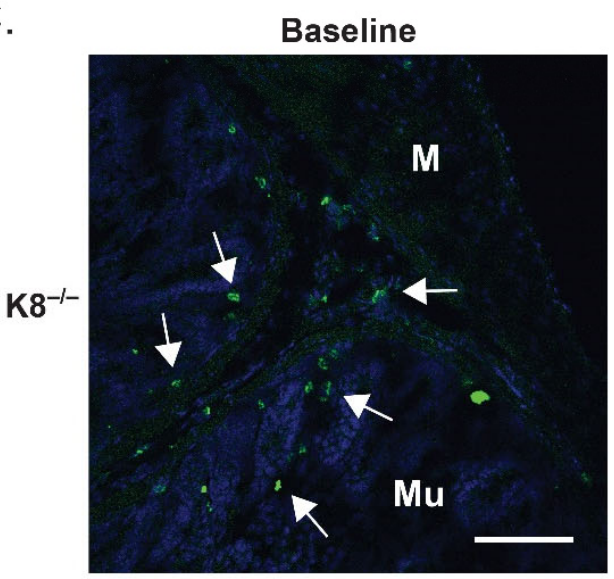

B.

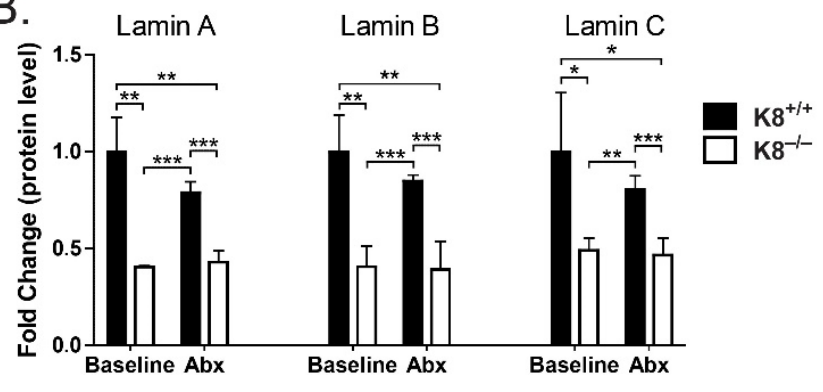

Antibiotics

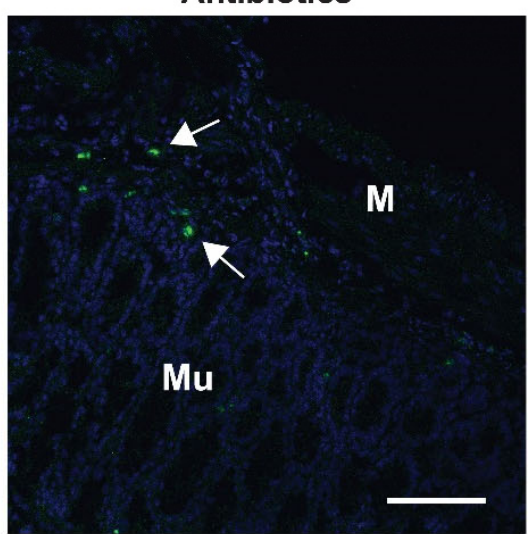

MPO Nuclei

Figure 4. Absence of the colonic microbiota does not affect lamin protein levels in $\mathrm{K}^{+/+}$and $\mathrm{K} 8^{-/-}$mouse colon epithelial cells. A) Lysates of crudely isolated colon epithelium from nontreated (baseline) and antibiotic-treated (imipenem and vancomycin as described in Materials and methods) $\mathrm{K}^{+/+}$and $\mathrm{K} 8^{-/-}$mice were immunoblotted for lamins $\mathrm{A}, \mathrm{B}$ and $\mathrm{C}$ and $\mathrm{K} 8$. Hsc70 was used as a loading control. B) The immunoblots were quantified and normalized to Hsc70 protein levels. The results represent the mean $(n=3$ for baseline and $n=4$ for antibiotic-treated mice) protein quantity \pm SD with significant differences shown as $*=p<0.05, * *=p<0.01$ and $* * *=p<0.001$. C) The inflammatory status of the colon in baseline and antibiotic-treated $\mathrm{K} 8^{-/-}$mice was assessed by the presence of myeloperoxidase (MPO)-positive neutrophils (white arrows). Nuclei (blue) were visualized with DRAQ5. Scale bar $=100 \mu \mathrm{m}$; Mu, mucosa; M, muscularis. 
A.

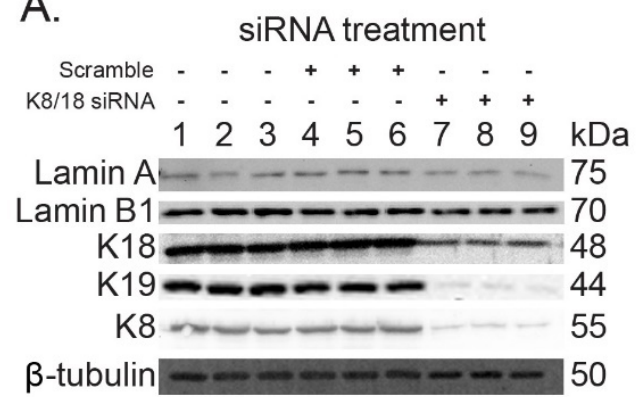

B.
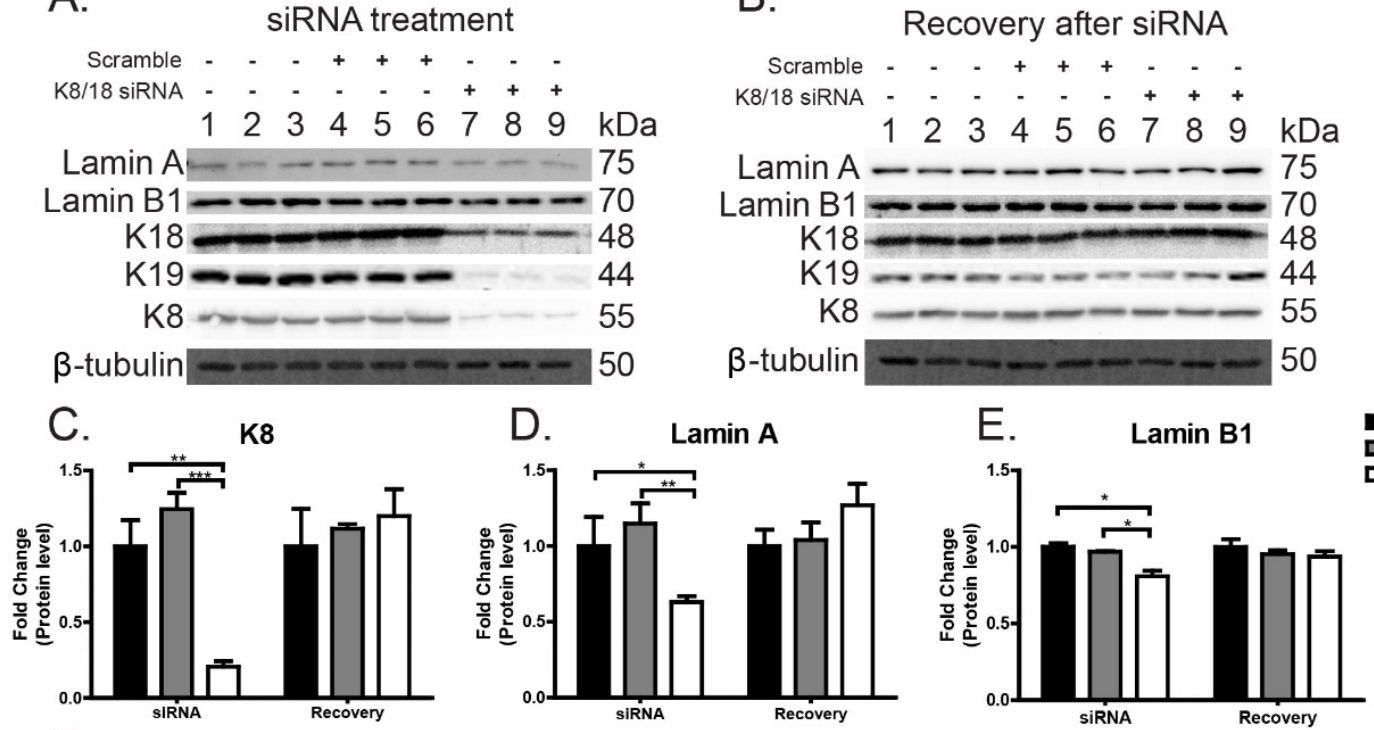

$\mathrm{F}$.

Lamin A/C

\section{Lamin B1}
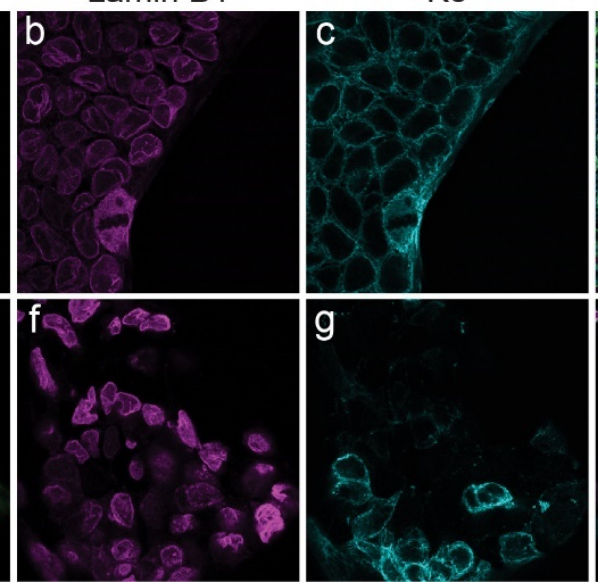

Merge

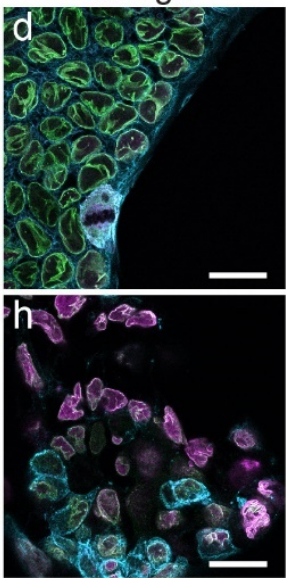

Figure 5. Caco-2 cells treated with K8/K18 siRNA exhibit reduced lamin protein levels, which can be rescued by re-expression of keratins. A) Mock-transfected (all reagents except siRNA), K8/K18 scramble siRNA-transfected and K8/K18 siRNA-transfected Caco-2 cells were immunoblotted for lamins A and B1, K8, K18 and K19. $\beta$-actin was used as a loading control. B) siRNA-treated cells were allowed to recover after siRNA-treatment and analyzed by immunoblotting for lamins A and B1, K8, K18 and K19. $\beta$-actin was used as a loading control. Recovery of the cells after siRNA-treatment led to re-expression of keratins and rescue of lamin expression. C-E) The immunoblots were quantified and normalized to $\beta$-actin and represent the mean $(\mathrm{n}=3)$ protein quantity $\pm \mathrm{SD}$ with significant differences shown as $*=\mathrm{p}<0.05, * *=\mathrm{p}<$ 0.01 and $* * *=p<0.001$. F) K8/K18 scramble siRNA- and K8/K18 siRNA-treated Caco-2 cells were immunostained for lamin A (green), lamin B1 (magenta) and K8 (cyan). Scale bar $=25$ $\mu \mathrm{m}$. 

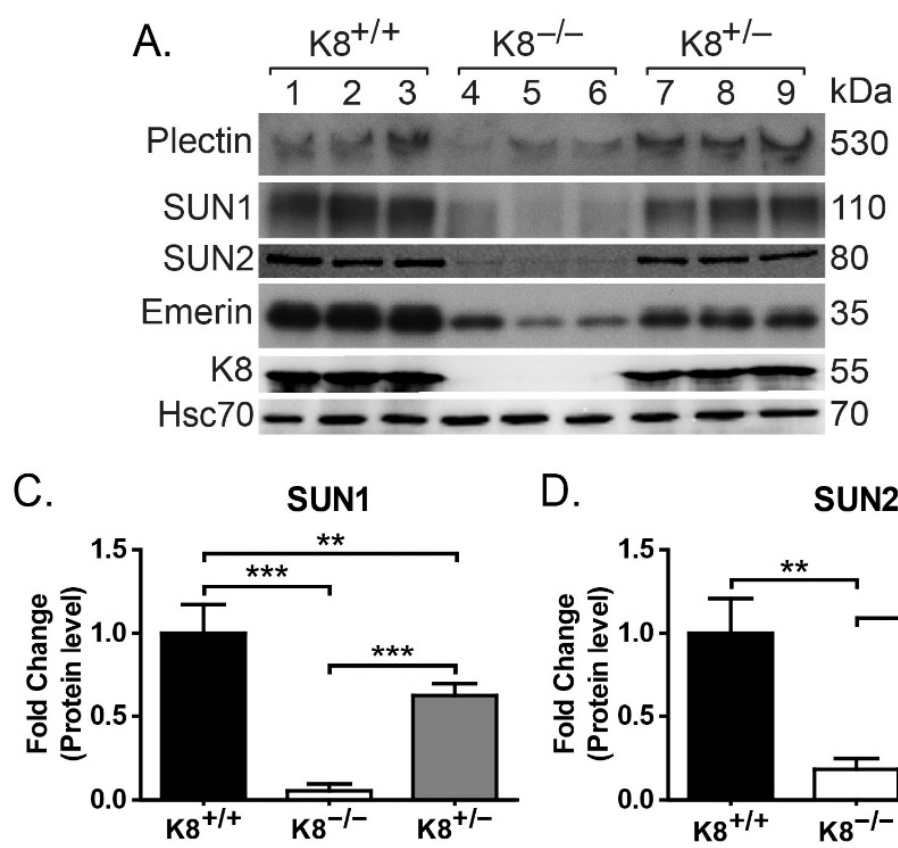

D.

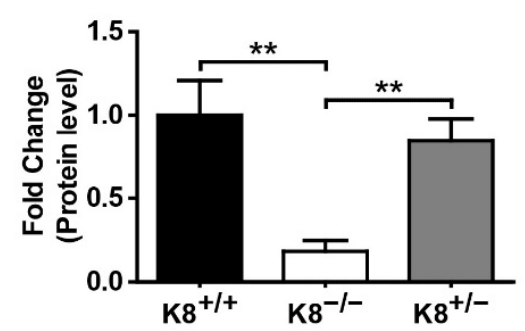

B.

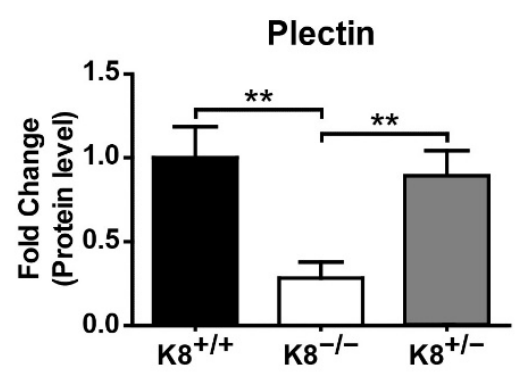

E.

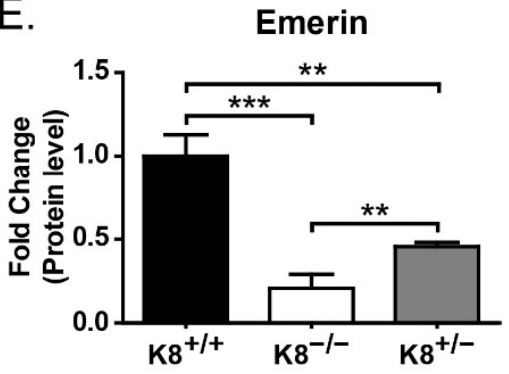

$\mathrm{F}$.

K18 IP

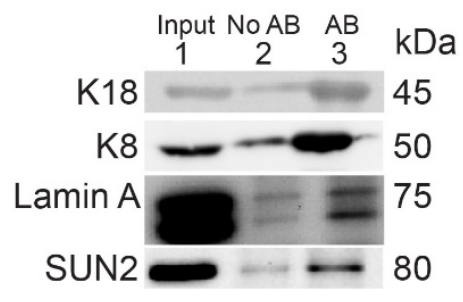

G. Lamin A IP

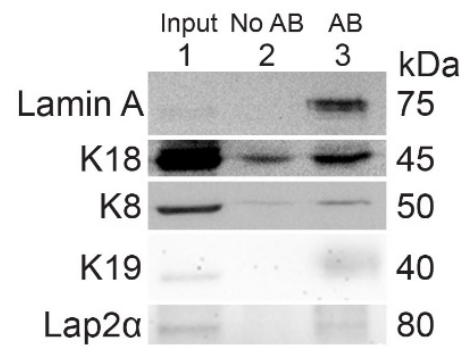

Figure 6. LINC protein levels are decreased in $\mathrm{K} 8^{-/-}$colon epithelial cells. A) Lysates of crudely isolated colon epithelium from $\mathrm{K}^{+/+}$(lanes 1-3), $\mathrm{K}^{-/-}$(lanes 4-6) and $\mathrm{K} 8^{+/-}$(lanes 79) mice $(n=3)$ were immunoblotted for plectin, nesprin-3, SUN1, SUN2, emerin and K8. Hsc70 was used as a loading control. B-E) The immunoblots were quantified and normalized to Hsc70 protein levels and represent the mean $(\mathrm{n}=3)$ protein quantity $\pm \mathrm{SD}$ with significant differences shown as $*=\mathrm{p}<0.05, * *=\mathrm{p}<0.01$ and $* * *=\mathrm{p}<0.001$. F-G) Caco-2 cell lysates (input) were used in immunoprecipitation assays where $\mathrm{K} 8 / \mathrm{K} 18$ (F) or lamin $\mathrm{A}(\mathrm{G})$ were immunoprecipitated using K18 or lamin A antibodies, respectively. Immunoprecipitates were immunoblotted for K8, K18, K19, lamin A, SUN2 and LAP2 $\alpha$. K8/K18 co-immunoprecipitated lamin A and SUN2, and lamin A co-immunoprecipitated K8, K18, K19 and LAP2 $\alpha$. No AB indicates a negative control sample, in which the immunoprecipitation step was performed without antibody. 
A.
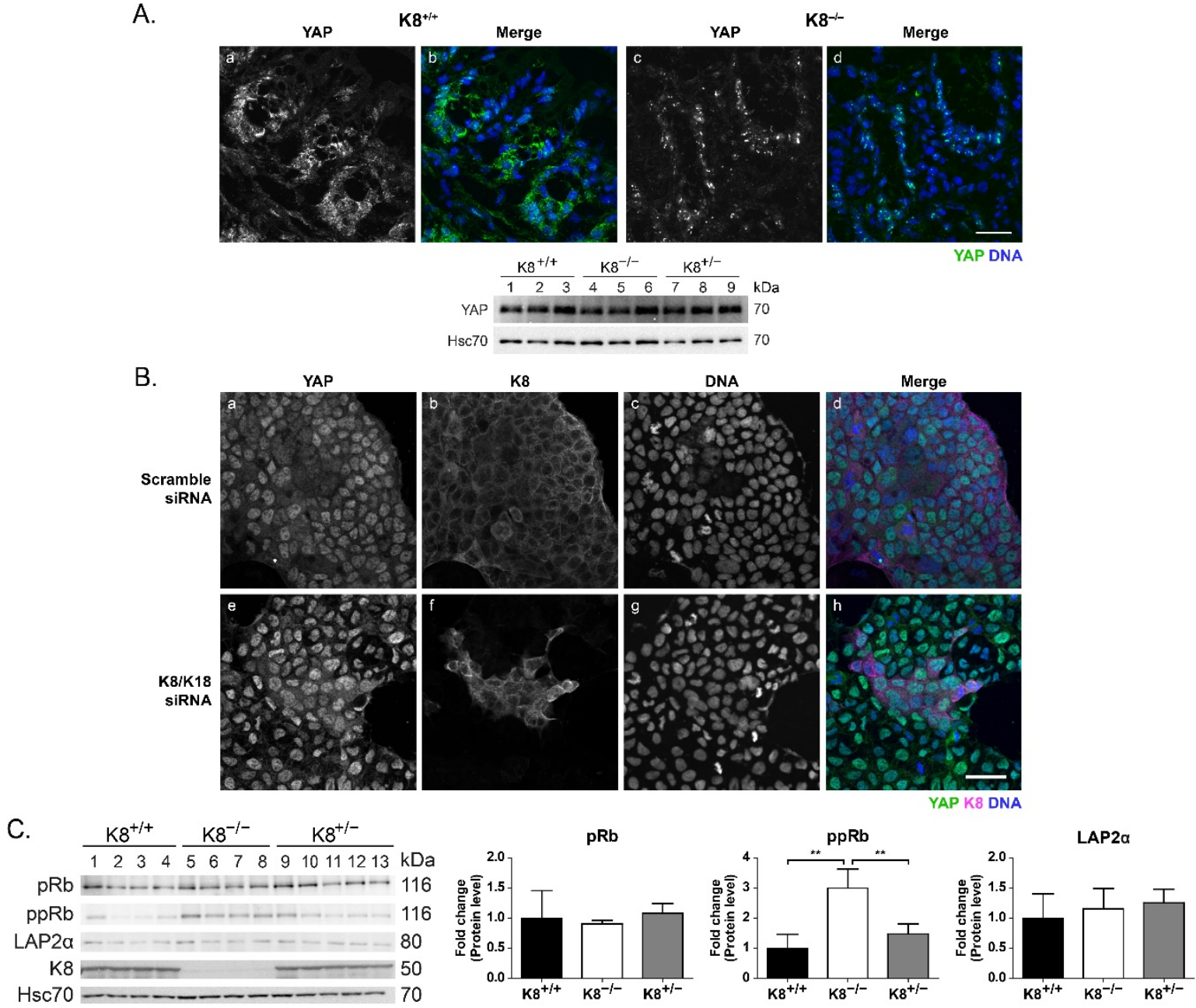

Figure 7. Loss of K8 correlates with increased nuclear translocation of YAP and hyperphosphorylation of $\mathrm{pRb}$ in colon epithelial cells. A) $\mathrm{K} 8^{+/+}$and $\mathrm{K} 8^{-/-}$mouse colon tissue cryosections were immunostained for YAP (green) and DNA (DRAQ5, blue). Scale bar $=25$ $\mu \mathrm{m}$. Lysates of crudely isolated colon epithelium from $\mathrm{K}^{+/+}$(lanes 1-3), $\mathrm{K}^{-1-}$ (lanes 4-6) and $\mathrm{K}^{+/-}$(lanes 7-9) mice $(\mathrm{n}=3)$ were immunoblotted for YAP. Hsc70 was used as a loading control. B) Caco-2 cells treated with K8/K18 scramble siRNA (negative control) or K8/K18 siRNA were immunostained for YAP (green), K8 (magenta) and DNA (DRAQ5, blue). Scale bar $=50 \mu \mathrm{m}$. C) Lysates of crudely isolated colon epithelium from $\mathrm{K} 8^{+/+}$(lanes 1-4), $\mathrm{K}^{-/-}$ (lanes 5-8) and $\mathrm{K}^{+/-}$(lanes 9-13) mice were immunoblotted for $\mathrm{pRb}$, phosphorylated $\mathrm{pRb}$ (ppRb; phosphor-Ser 807 and phosphor-Ser 811), LAP2 $\alpha$, and K8. Hsc70 was used as a loading control. The immunoblots were quantified and normalized to Hsc 70 protein (or against $\mathrm{pRb}$ for $\mathrm{ppRb}$ ) levels and represent the mean protein quantity $\pm \mathrm{SD}$ with significant differences shown as $* *=p<0.01$. 

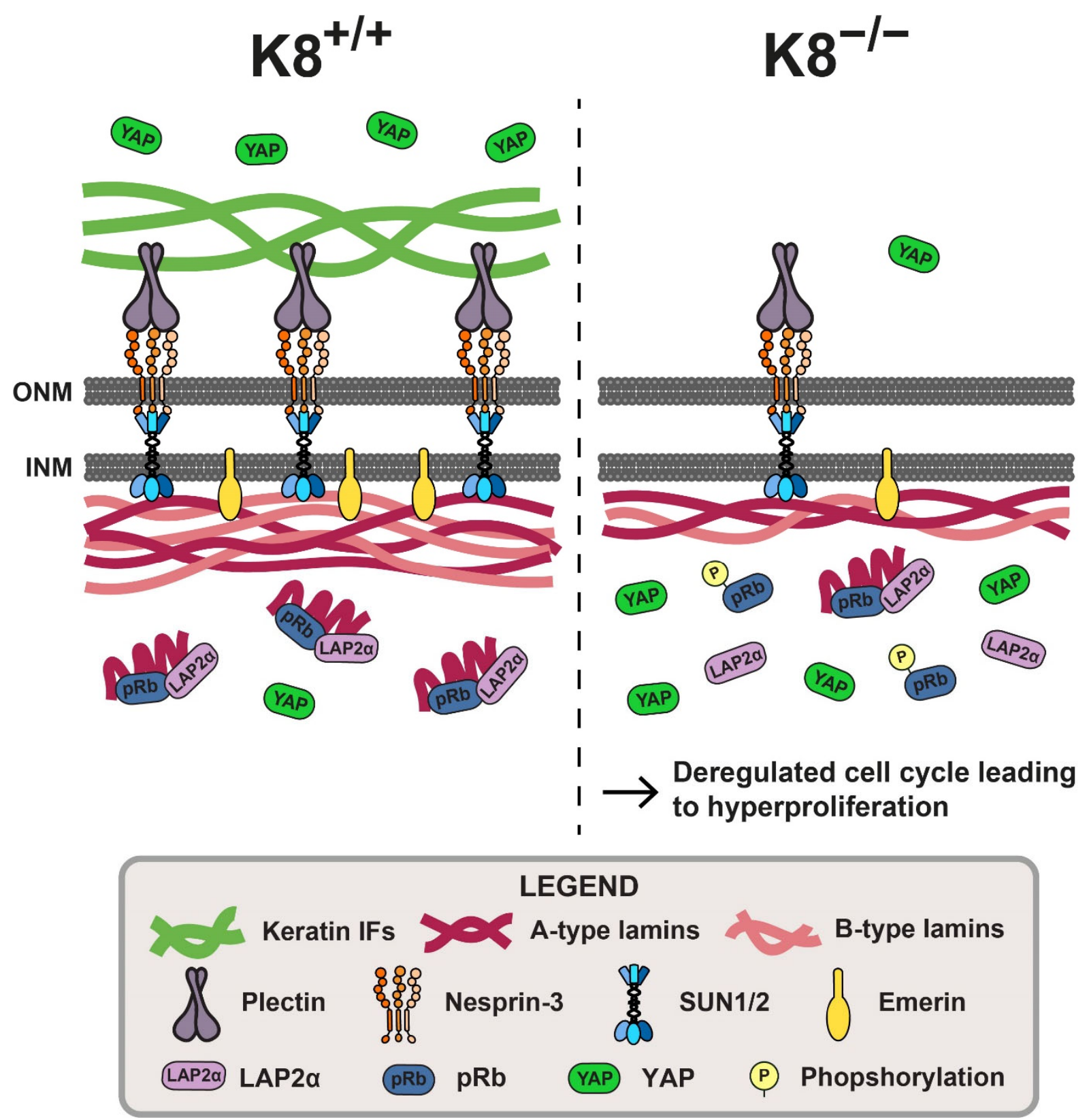

Figure 8. Cytoplasmic simple epithelial keratins complex with nuclear lamins, LINC complex proteins and lamin-associated proteins, maintaining keratin-nuclear lamina coupling and proliferation homeostasis in colonic epithelial cells. In this summary schematic, the findings of this study are summarized. In healthy colon epithelial cells $\left(\mathrm{K}^{+/+}\right)$, cytoplasmic $\mathrm{K} 8$-containing keratin IFs couple with and/or stabilize plectin, LINC complex proteins, lamins and laminassociated proteins, thus helping maintain nucleocytoskeletal coupling and nuclear function. Loss of cytoplasmic keratins $\left(\mathrm{K}^{-/-}\right)$in colon epithelial cells correlates with decreased plectin, LINC complex protein, lamin and lamin-associated protein levels, which likely disrupts these nuclear membrane complexes. Significantly, the decreased A-type lamin levels in $\mathrm{K}^{-/-}$ colonocytes correlates with, and allows for, increased hyperphosphorylation of $\mathrm{pRb}$, which in turn promotes cell cycle progression. Furthermore, K8-deficient colonocyte nuclei exhibit increased accumulation of the mechanosensor YAP. Together, these changes may contribute to the hyperproliferation phenotype observed in $\mathrm{K}^{-/-}$mouse colon and define a role for cytoplasmic keratins in nuclear integrity and function. 


\section{Supplemental Figures and Legends}

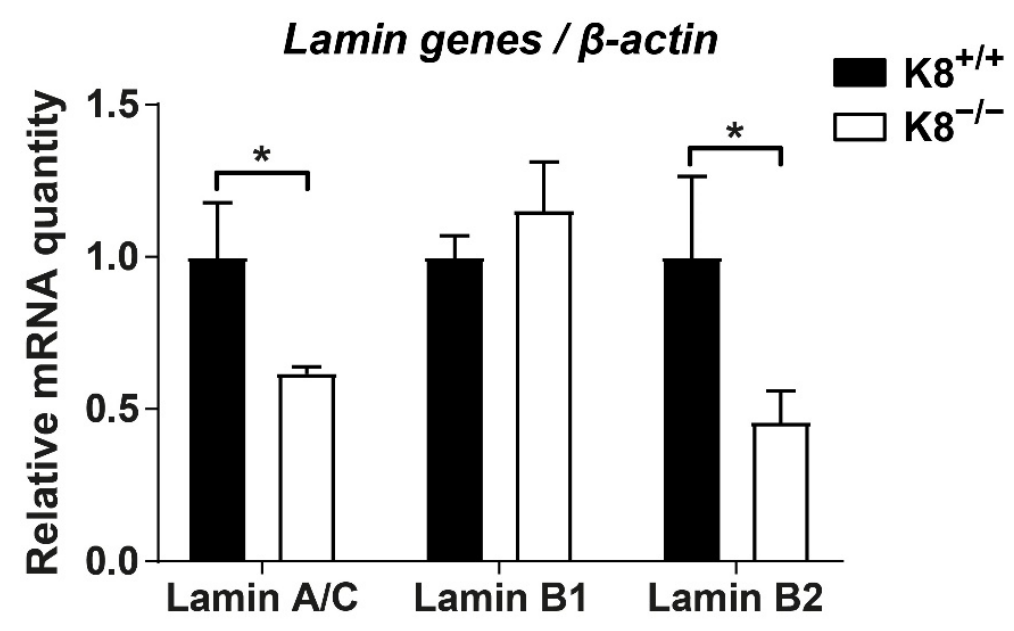

Supplemental figure 1. Lamin A/C and B2 mRNA levels are decreased in $\mathrm{K}^{-/-}$mouse colon. The mRNA levels of lamins $\mathrm{A} / \mathrm{C}, \mathrm{B} 1$ and $\mathrm{B} 2$ in $\mathrm{K} 8^{+/+}$and $\mathrm{K}^{-/-}$mouse colon total lysates were analyzed by qRT-PCR. The results were normalized to $\beta$-actin and represent the average $(\mathrm{n}=3)$ fold change $\pm \mathrm{SD}$, with significant differences shown as $*=p<0.05$. 
A.
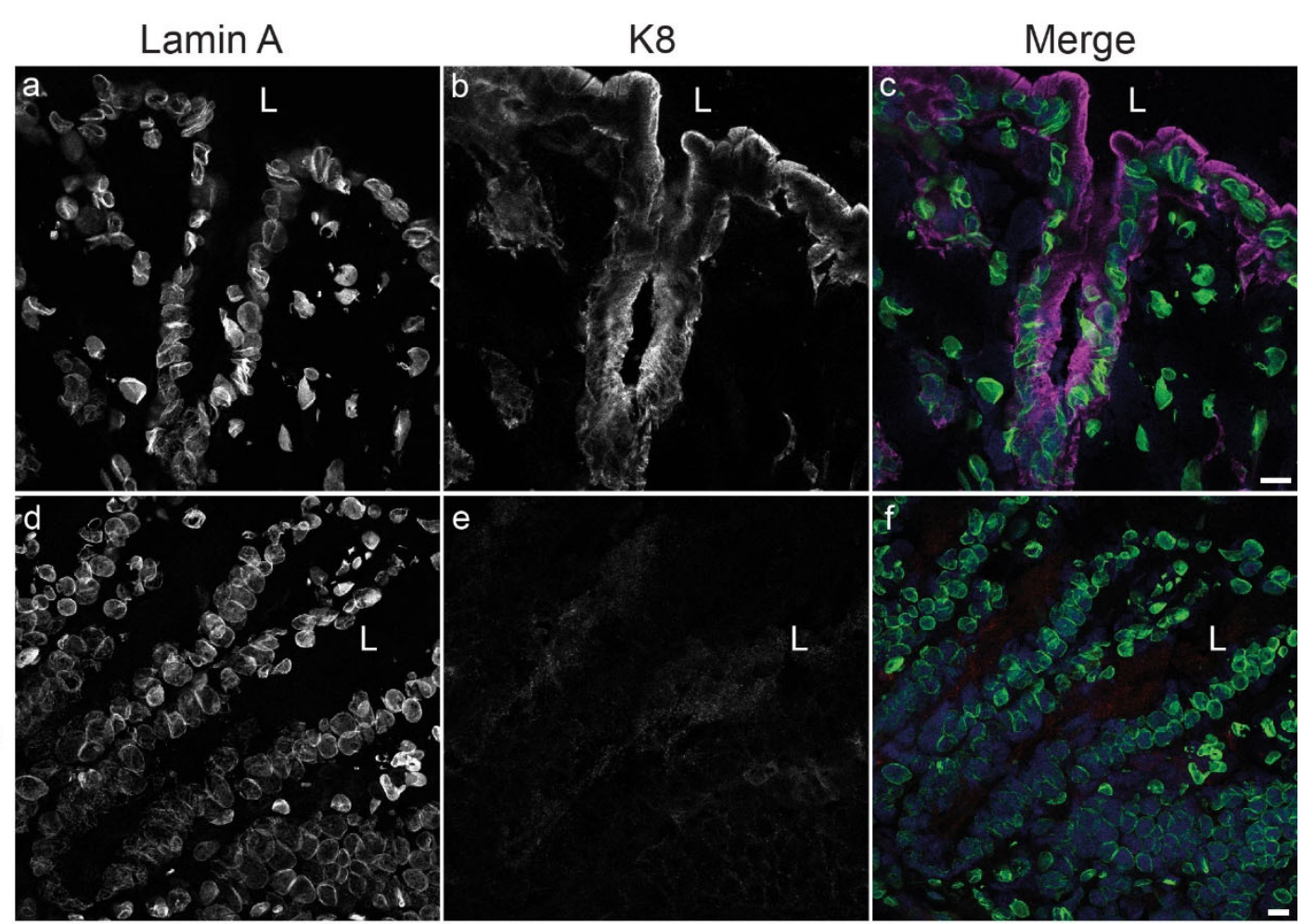

B.

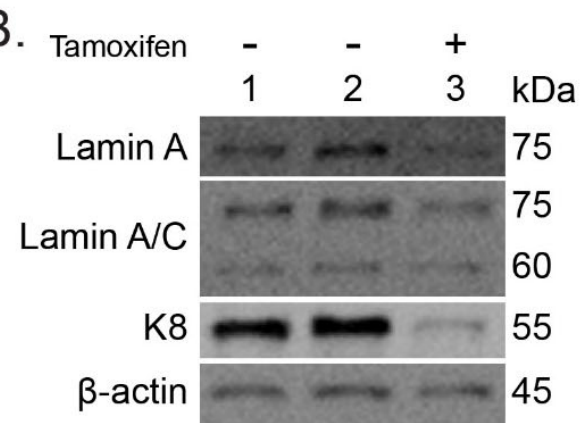

Lamin A K8 DNA

Supplemental figure 2. Intestinal epithelial cell-specific knockdown of $\mathrm{K} 8$ in mice exhibits colon epithelial cell-specific lamin A downregulation. A) $\mathrm{K} 8^{\text {flox } / \text { flox }}$ and $\mathrm{K} 8^{\text {flox/flox}}$;Villin-Cre mouse colon tissue cryosections were immunostained for lamin A (green), K8 (magenta) and DNA (DRAQ5, blue). Scale bar $=10 \mu \mathrm{m} . \mathrm{B}$ ) Colon organoids from K8 $8^{\text {flox/flox}}$; Villin-Cre-ER ${ }^{\mathrm{T} 2}$ mice were isolated, grown in $3 \mathrm{D}$ in matrigel, and treated with $(+)$ or without $(-)$ tamoxifen to induce $\mathrm{K} 8$ knockdown ex vivo. Lysates of the organoids were immunoblotted for lamins A and $\mathrm{A} / \mathrm{C}$ and $\mathrm{K} 8$. $\beta$-actin was used as a loading control. 
A.

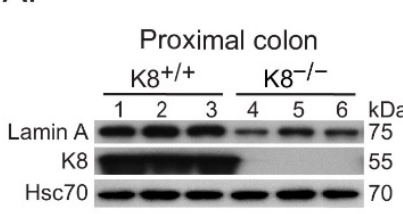

C.

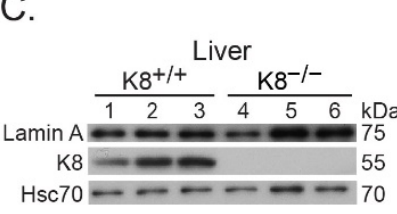
Lamin A proximal colon B.
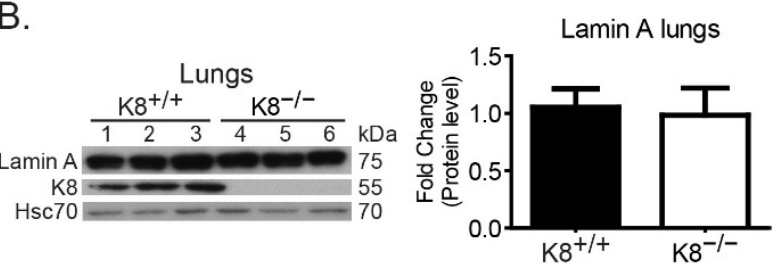

D.
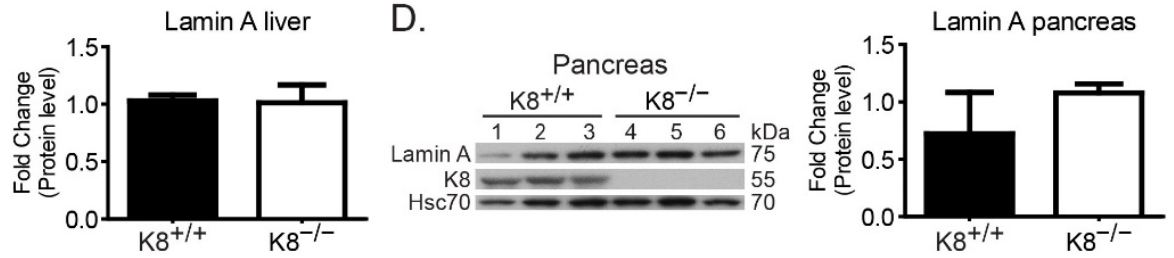

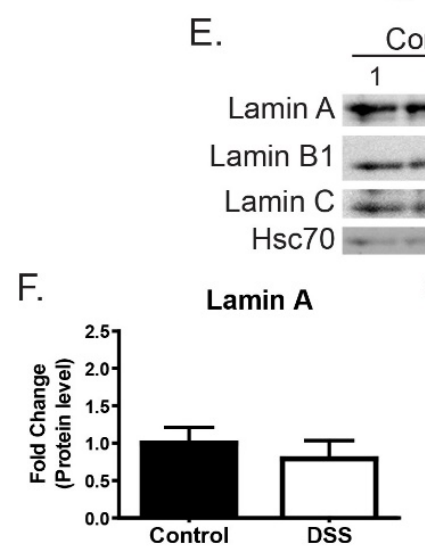

$\frac{\text { Control }}{123}$

\begin{tabular}{lll}
\multicolumn{5}{c}{ DSS } \\
\hline 4 & 5 & 6
\end{tabular}

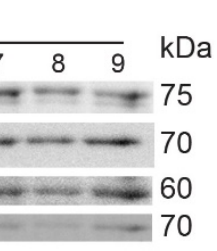

G.

H.
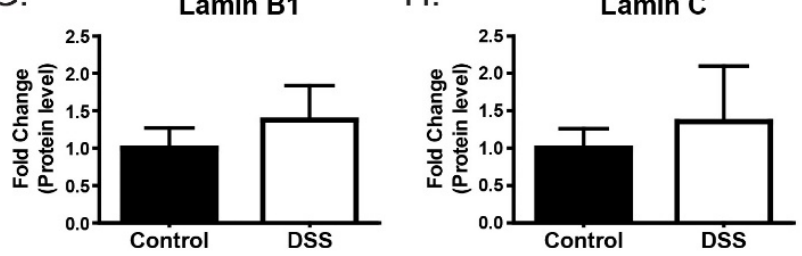

Supplemental figure 3. Lamin downregulation is colon-specific in $\mathrm{K} 8^{-/-}$mice and not caused by inflammation. Total lysates of proximal colon, lung, liver and pancreas from $\mathrm{K}^{+/+}$(lanes 13 ) and $\mathrm{K}^{-/-}$(lanes 4-6) mice $(\mathrm{n}=3)$ were immunoblotted for lamin $\mathrm{A}$ and $\mathrm{K} 8$. Hsc70 was used as a loading control. The immunoblots were quantified and normalized to Hsc70 protein levels and represent the mean $(\mathrm{n}=3)$ protein quantity $\pm \mathrm{SD}$ with significant differences shown as $* * *$ $=\mathrm{p}<0.001$. E-H) Total lysates of colon from untreated (control; lanes 1-3) and DSS-treated (2\%, 8 days) $\mathrm{K}^{+/+}$(lanes 4-9) mice were immunoblotted for lamins A, B1 and C. Hsc70 was used as a loading control. The immunoblots were quantified and normalized to Hsc70 protein levels and represent the mean $(n=3)$ protein quantity \pm SD. 
A.

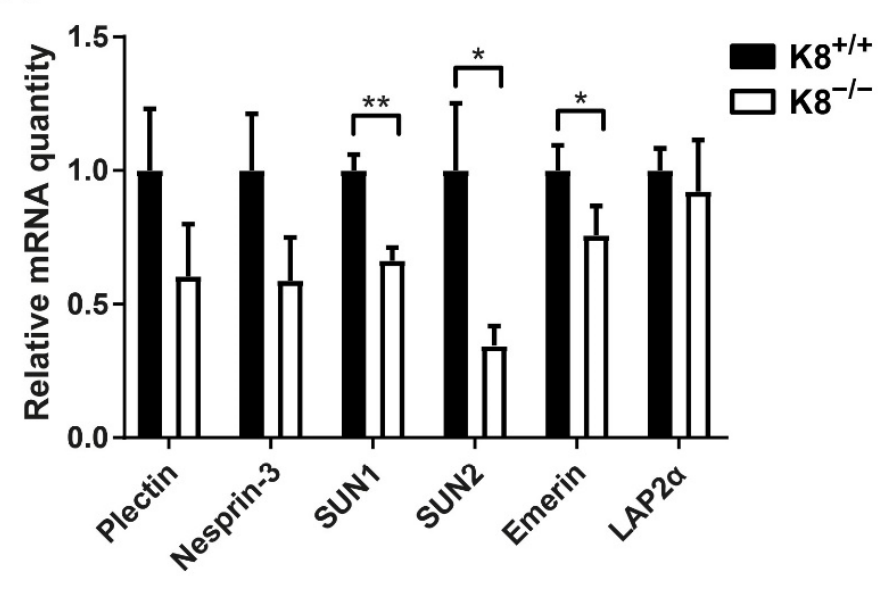

B.
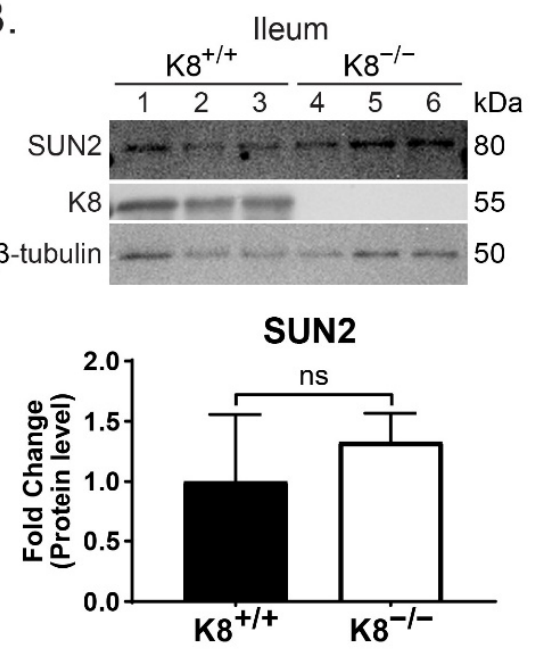

C.
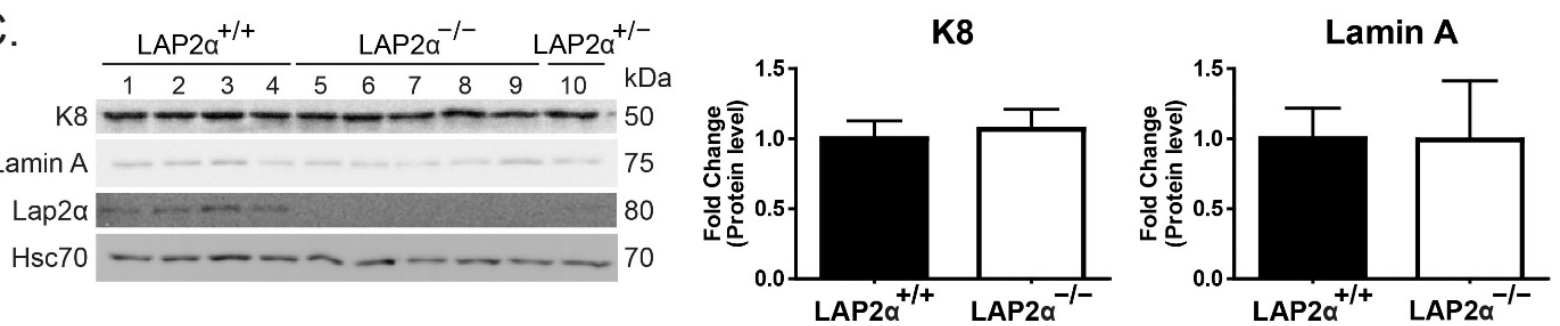

Supplemental figure 4. LINC protein down-regulation is colon-specific in $\mathrm{K}^{-/-}$mice and partly due to reduced gene expression, while keratins and lamin A are unaltered in LAP2 $\alpha^{-1-}$ mouse colon. A) The mRNA levels of plectin, nesprin-3, SUN1, SUN2, emerin and LAP2 $\alpha$ in $\mathrm{K}^{+/+}$and $\mathrm{K} 8^{-/-}$mouse colon total lysates were analyzed by qRT-PCR. The results were normalized to $\beta$-actin and represent the average $(\mathrm{n}=3)$ fold change $\pm \mathrm{SD}$, with significant differences shown as $*=\mathrm{p}<0.05$ and $* *=\mathrm{p}<0.01$. B) Total lysates of ileum from $\mathrm{K} 8^{+/+}$(lanes $1-3)$ and $\mathrm{K}^{-/-}$(lanes 4-6) mice were immunoblotted for SUN2 and K8. $\beta$-tubulin was used as a loading control. The immunoblots were quantified and normalized to $\beta$-tubulin protein levels and represent the mean $(\mathrm{n}=3)$ protein quantity $\pm \mathrm{SD}$. C) Lysates of crudely isolated colon epithelium from LAP2 $\alpha^{+/+}$(lanes 1-4), LAP2 $\alpha^{-/}$(lanes 5-9) and LAP2 $\alpha^{+/-}$(lane 10) mice were immunoblotted for K8, lamin A and LAP2 $\alpha$. Hsc70 was used as a loading control. The immunoblots were quantified and normalized to Hsc70 protein levels and represent the mean $\left(\mathrm{n}=4\right.$ for $\mathrm{LAP} 2 \alpha^{+/+}$and $\mathrm{n}=5$ for $\left.\mathrm{LAP} 2 \alpha^{-/}\right)$protein quantity $\pm \mathrm{SD}$. 
A.

B.

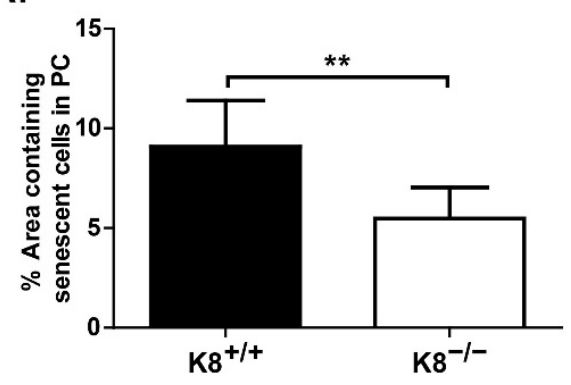

$\mathrm{K}^{+/+}$

PC
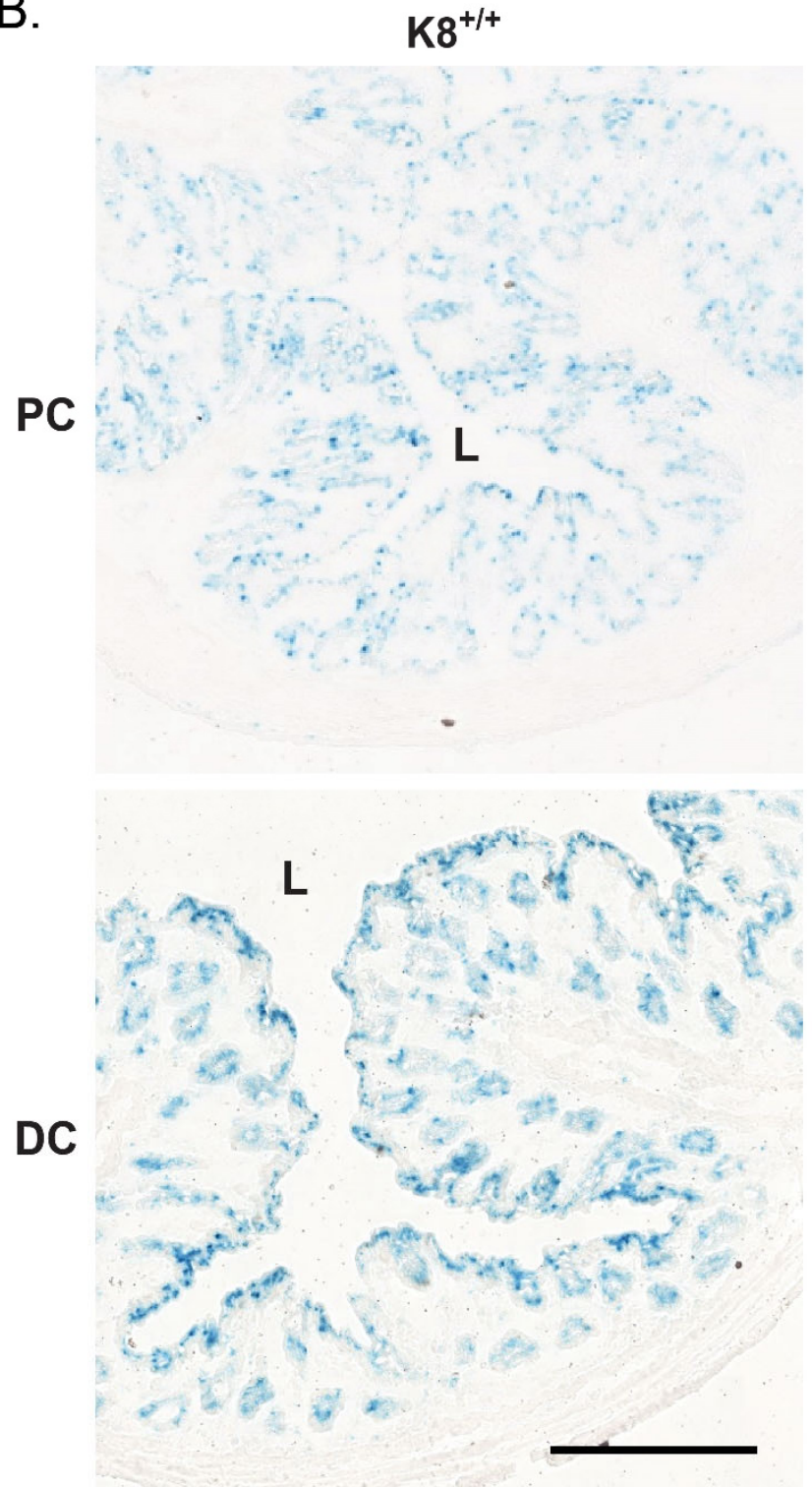

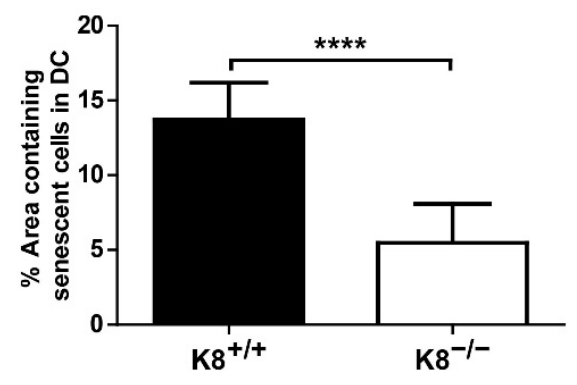

$\mathrm{K}^{-1-}$

Supplemental figure 5. Cell senescence is diminished in the $\mathrm{K} 8^{-/-}$mouse colon. Tissue sections of proximal (PC) and distal (DC) colon from $\mathrm{K}^{+/+}$and $\mathrm{K} 8^{-/-}$mice were analyzed for the presence of senescent cells by senescence-associated $\beta$-galactosidase staining. A) The number of senescent cells was quantified with ImageJ software by dividing the area of senescence-associated $\beta$-galactosidase-positive blue signal with the total area of the tissue section. B) Representative images of $\mathrm{K}^{+/+}$and $\mathrm{K}^{-/-} \mathrm{PC}$ and DC with senescent cells in blue. Scale bar $=500 \mu \mathrm{m} . \mathrm{L}=$ lumen. 
bioRxiv preprint doi: https://doi.org/10.1101/2020.06.22.164467; this version posted June 22, 2020. The copyright holder for this preprint (which was not certified by peer review) is the author/funder, who has granted bioRxiv a license to display the preprint in perpetuity. It is made available under aCC-BY-NC-ND 4.0 International license.

Supplemental table 1. Primers and Universal ProbeLibrary (UPL) probes used for quantitative RT-PCR.

\begin{tabular}{|c|c|c|c|}
\hline Gene & Forward primer & Reverse primer & UPL probe \\
\hline $\operatorname{Lamin} \mathrm{A} / \mathrm{C}$ & 5'-GAG CAA AGT GCG TGA GGA GT-3' & 5'-CAA CAA GTC CCC CTC CTT CT-3' & $\# 17$ \\
\hline Lamin B1 & 5'-TGG TGA AGA TGT GAA GGT TAT ATT G-3' & 5'-TGA AGA CTG TGC TTC TCT GAG C-3' & $\# 55$ \\
\hline Lamin B2 & 5'-GGC TGC AGA TTG AAA TTG G-3' & 5'-GCT CAC CTT CCC GCT TCT-3' & \#72 \\
\hline Plectin & 5'-AGC TGG AAC AGG TCC GAA G-3' & 5'-CAC CAA GCT GAT GGT CTT GA-3' & $\# 80$ \\
\hline Nesprin 3 & 5'-TCA CCT ACA TGA CCC ACT GC-3' & 5'-GGG CCA GCA GGT ACT CAC T-3' & $\# 5$ \\
\hline SUN1 & 5'-TCA CCT CGA GTG GTG ATC C-3' & 5'-TAC CCC TGG GAA CCT TTG A-3' & $\# 107$ \\
\hline SUN2 & 5'-GAT CGT CCA GGC CTC TCA-3' & 5'-GTC CCA GCT CCT TCA CAG AG-3' & \#79 \\
\hline Emerin & 5'-GGA CCT CAC TTG TAG ATG CTG AT-3' & 5'-TCT AAA GAA GAG AAA ATG TCA TCA CG-3' & $\# 9$ \\
\hline LAP $2 \alpha$ & 5'-TCC TCT АСТ СCT CTT CCA ACA GTC-3' & 5'-GCG GAC TTC ACT TTC TTG TGT-3' & $\# 6$ \\
\hline$\beta$-actin & 5'-TGG CTC CTA GCA CCA TGA AGA-3' & 5'-GTG GAC AGT GAG GCC AGG AT-3' & \#56 \\
\hline
\end{tabular}

